\title{
Análisis multicriterio del modelo de gestión de la Reserva Biológica Bosque Nuboso Monteverde, Puntarenas, Costa Rica
}

\author{
Rodolfo Antonio Hernández-Chaverri, M.Eng. ${ }^{1}$, Fabricio Camacho-Céspedes ${ }^{2} \&$ \\ Jeannette Hernandez-Barrero ${ }^{3}$ \\ 1. Universidad Estatal a Distancia, Costa Rica. Cátedra de Ciencias Químicas para Ingeniería. Laboratorio de \\ Investigaciones Bioenergéticas y Ambientales. Correo: rohernandez@uned.ac.cr \\ 2. M.Sc. Universidad de Georgia, Campus Costa Rica. Correo: fabricio@uga.edu \\ 3. M.Sc. Fundación de Humedales, Colombia. Correo: sandrahe@fundacionhumedales.org
}

Recibido: 30 de noviembre, 2016

Aceptado: 01 de marzo, 2017

\begin{abstract}
RESUMEN
Desde sus orígenes y a través de los años, la Reserva Bosque Nuboso Monteverde se han convertido en un referente internacional en cuanto a la conservación de los recursos naturales y la biodiversidad. La reserva no solamente ha logrado la protección de más de 4200 hectáreas de Bosque Nuboso, uno de los ecosistemas más amenazados por la deforestación y el cambio climático, sino que lo ha logrado en forma participativa e inclusiva con la comunidad local e internacional. El modelo de gestión de la reserva se enfoca en los tres pilares de la sostenibilidad: ambiental, social y económico. El modelo es robusto, pero es amenazado por su fuerte dependencia a los ingresos generados por el programa de ecoturismo. El equipo de gestión del área protegida debe buscar otras fuentes de financiamiento para fortalecer la sostenibilidad económica a mediano y largo plazo.
\end{abstract}

Palabras clave: Monteverde, Bosque Nuboso, sostenibilidad, conservación, gestión.

\footnotetext{
ABSTRACT

Throughout the years from its inception, the Monteverde Cloud Forest Reserve has become an international model in natural resource management and biodiversity conservation. Not only has the reserve been able to protect more than 4,200 hectares of cloud forest, one of Costa Rica's most threatened ecosystems, but it has been able to do so with the participation and involvement of the local and international community. The management model is focused on the three pillars of sustainability: environmental, social and economic. The model is robust; however, it is threatened by its heavy dependency on the economic resources generated from its ecotourism program. Therefore, the management team must develop other economic sources in order to strengthen the reserve's economic sustainability in the mid and short term.
}

Key words: Monteverde, Cloud Forest, sustainability, conservation, management.

\section{Introducción}

El siguiente análisis de caso tiene como objetivo evaluar el nivel de sostenibilidad, entendida como el balance en el rendimiento ambiental y socioeconómico de la Reserva Bosque Nuboso Monteverde; para así, poder identificar las áreas donde ésta se ve amenazada y explicar el por qué, ésta reserva ha sido un ejemplo exitoso de conservación y desarrollo sostenible. Para esto se llevará a cabo una evaluación del proyecto bajo las tres dimensiones teóricas de la sostenibilidad (ambiental, social, económica), a través de un análisis desagregado de indicadores empleando la metodología sobre Mapas Multicriterio, la cual tiene una amplia efectividad para evaluar la sostenibilidad en sistemas de manejo (Astier et al 2008). Bajo dicha metodología, se seleccionarán aquellos indicadores que representan una función crítica en la red de relaciones del sistema que se está evaluando (Astier et al 2008).

\section{Antecedentes}

A principios de los años mil novecientos cincuenta, un grupo de familias cuáqueras provenientes del sur de los Estados Unidos compró un terreno en la parte alta de la Cordillera de Tilarán, Puntarenas, Costa Rica, donde fundaron 
la comunidad de Monteverde (Wheelwright y Nadkarni 2014). Este grupo de ciudadanos extranjeros se naturalizaron como costarricenses e hicieron amistad con las familias que ya vivían en la zona y paulatinamente fueron transformando un área de las 1200 hectáreas de bosque, en fincas de producción de leche y agricultura de subsistencia. Estos finqueros se caracterizaron por planificar el uso de sus terrenos, de los cuales solo ocuparon un poco menos de $2 / 3$ partes para sus actividades productivas y residenciales (Acuña et al. 2006), dejando el resto del área para protección y donde posteriormente establecieron una reserva comunitaria para el cuidado de las nacientes de agua que le proveerían de ese vital líquido tanto para sus actividades domésticas como productivas. En un principio, esa reserva estuvo conformada por un bloque continuo de bosque nuboso de 554 hectáreas al cual denominaron el Bosque Eterno de Monteverde (Bermúdez y Hernández 2005).

A finales de la década de los sesenta, un grupo de investigadores del Centro Científico Tropical (en adelante CCT), visitó la zona de Monteverde con el fin de conocer la diversidad biológica de esa parte del país. Estos investigadores quedaron asombrados de la biodiversidad del lugar y recomendaron a la comunidad cuáquera realizar esfuerzos para extender el área de la "reserva de agua" previamente establecida (Bermúdez y Hernández 2005). A principios de los setenta, en función de la recomendación del CCT, el ornitólogo y posterior fundador de la Reserva Biológica Bosque Nuboso Monteverde (en adelante RBBNMV o Reserva Monteverde), Dr. George Powell, residente en esa época en la zona e investigador del Quetzal (Pharomacros moccino), logró la donación de 328 hectáreas por parte de una empresa minera, dueña de un terreno boscoso adyacente al Bosque Eterno, para la consolidación de la Reserva Monteverde. Para que la donación del terreno fuera efectiva, se exigió la implementación de una dependencia administrativa, razón por la cual se solicitó al CCT asumir esa función desde el año 1973 (Bermúdez y Hernández 2005).

Bajo el sistema actual, la Reserva Monteverde es un área protegida privada de
4200 hectáreas de bosque nuboso tropical montano (BNTM). se localiza al noroeste de Costa Rica sobre la Cordillera Volcánica de Tilarán a 1534 msnm (Figura 1, con coordinadas de latitud de $10.302429^{\circ}$ y longitud de $-84.795369^{\circ}$ ). Se encuentra entre las provincias de Puntarenas y Alajuela, y su principal acceso es a través de la comunidad de Monteverde, la cual forma parte del distrito número 10 del Cantón Central de Puntarenas (Wheelwright y Nadkarni 2014).

El clima de la región de Monteverde está determinado por los vientos alisios que entran a Costa Rica cargados de humedad por el Noreste, desplazándose desde el Mar Caribe hacia el Océano Pacífico, los cuales, al encontrarse con la región montañosa de la cordillera, depositan una gran cantidad de precipitación en forma de neblina y llovizna. La abundante precipitación y humedad en Monteverde juegan un papel relevante en la composición y dinámica del ecosistema, el cual cumple una función clave en la provisión de agua fresca a nivel de cuenca en ambas vertientes; así como, en la regulación del ciclo hidrológico (Toledo 2009; Armenteras et al. 2007).

En términos de biodiversidad, los bosques nubosos, incluyendo el de Monteverde, son ecosistemas prioritarios en la conservación a escala mundial, debido a la riqueza de especies de fauna y flora que albergan, especialmente de plantas epífitas vasculares y no vasculares, así como de aves, anfibios e invertebrados, muchos de los cuales están severamente amenazados y/o son de carácter endémico (Armenteras et al 2007).

La flora y fauna de la reserva es característica de cuatro zonas de vida: el bosque pluvial Premontano, el bosque pluvial Montano Bajo, el bosque muy húmedo Montano Bajo, y el bosque muy húmedo Premontano. No se cuenta con datos exactos del número de especies de flora presentes en la reserva; sin embargo, se estima la presencia de aproximadamente un tercio de la flora de Costa Rica, es decir más de 3200 especies de plantas y árboles. La Reserva ha sido catalogada como el sitio con la diversidad de orquídeas más alta del planeta (con más de 500 especies) e igualmente se destaca que cerca del $10 \%$ de las especies 


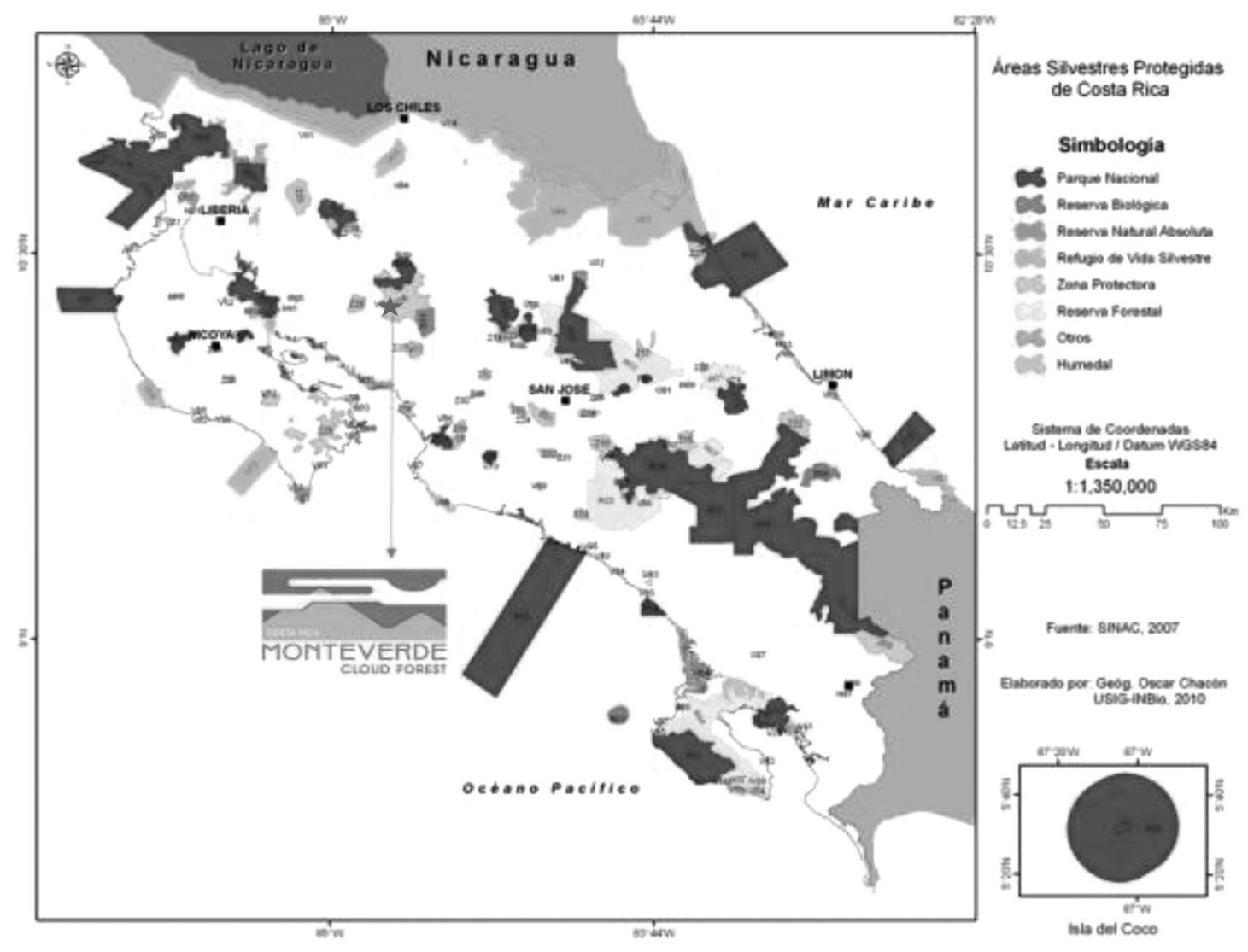

Figura 1. Ubicación geográfica de la Reserva Biológica Bosque Nuboso Monteverde. Fuente. Reserva Biológica Bosque Nuboso Monteverde. Chacón (2010).

de flora son endémicas de la Cordillera de Tilarán (Bermúdez y Hernández 2007).

A nivel de fauna, la biodiversidad es de igual forma muy alta en Monteverde. Por ejemplo, a nivel de anfibios y reptiles se reportan 161 especies. En cuanto a aves se establece que de las 450 especies reportadas, 91 especies $(21 \%)$ son migratorias neotropicales y 68 son migratorias altitudinales. La lista de mamíferos que incluyen elementos tanto de Norte y Suramérica, está conformada por cerca de 98 especies que incluyen murciélagos, marsupiales, felinos y venados entre otros (Bermúdez y Hernández, 2007).

La Reserva Monteverde está circunscrita al bloque de reservas públicas y privadas de la Zona Protectora Arenal Monteverde al norte del país. Además, está adscrita a la Reserva de la Biosfera Agua y Paz, así como de la Red de Reservas Privadas de Costa Rica.

Las principales amenazas del bosque Nuboso de Monteverde son la fragmentación de hábitat, principalmente hacia la vertiente Pacífica; así como, la variabilidad climática (Wheelwright y Nadkarni 2014). En función de combatir la fragmentación del hábitat la administración de la Reserva ha sido el actor principal en el establecimiento del Corredor Biológico Pájaro Campana, el cual busca reestablecer la conectividad boscosa estructural del Bosque Nuboso al Manglar de Puntarenas (Figura 2), atendiendo a las necesidades de restauración de hábitat ripario y al empoderamiento de las comunidades dentro del territorio para fomentar un desarrollo integral entre el ser humano y la naturaleza (Corredor Biológico Pájaro Campana 2011). 


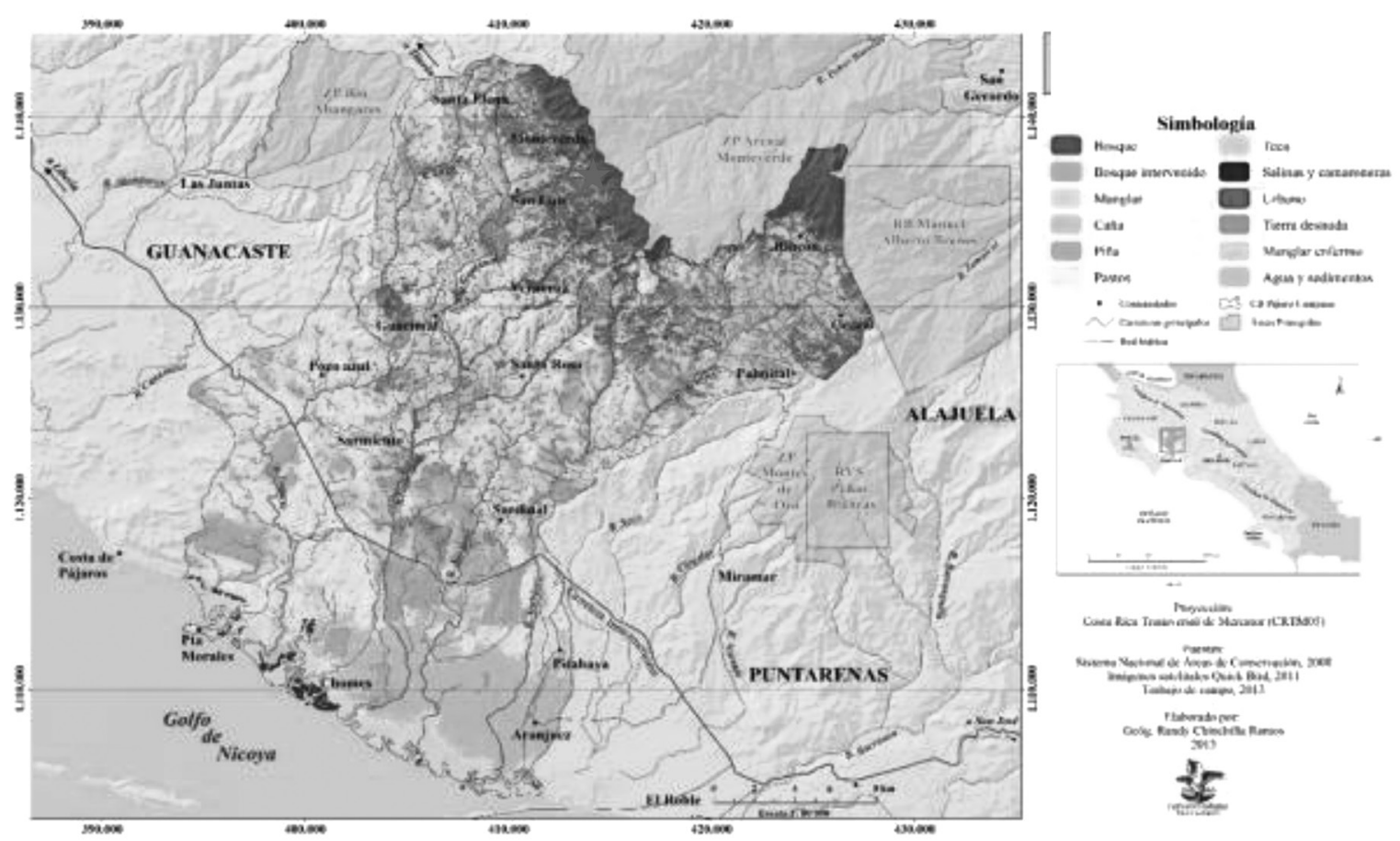

Figura 2. Ubicación de la Reserva Biológica Bosque Nuboso Monteverde. Fuente. CBPC 2013 (2008).

\section{Modelo de gestión}

La Reserva Monteverde es un proyecto gestionado por el Centro Científico Tropical (CCT), organización costarricense sin fines de lucro que se dedica a la investigación y el manejo de recursos naturales, así como a la administración de proyectos de conservación. En la actualidad, el CCT administra, además de la Reserva Monteverde, tres áreas protegidas ubicadas en San Luis de Monteverde, Sarapiquí y Pérez Zeledón, las cuales conforman el sistema de reservas privadas del CCT.

Cabe resaltar que dicha red es financiada por medio de los recursos generados en Monteverde, donde la principal fuente de ingresos es a través del turismo que visita el área protegida y que paga un canon de acceso de $\$ 20$ por persona si es extranjero, $\$ 10$ si es estudiante extranjero, $\$ 7$ si es costarricense y $\$ 5$ si es estudiante costarricense. Además, la reserva posee un albergue de montaña y una estación biológica la cual es utilizada por grupos de estudiantes de biología tropical e investigadores tanto nacionales como internacionales. Cabe hacer mención, que la visitación anual promedio de la Reserva Monteverde es de setenta mil personas (Bermúdez y Hernández 2007).

El manejo de la Reserva Monteverde tiene un enfoque ecosistémico e integral a través de un plan de manejo que es monitoreado y evaluado en forma adaptativa (Bermúdez y Hernández (2005). En este sentido, según Bermúdez y Hernández (2005), los principales objetivos del área protegida son: i) Conservar una muestra representativa del ecosistema de bosque nuboso en la Cordillera de Tilarán, ii) Conservar las especies de flora y fauna sobresalientes, endémicas y en peligro de extinción, características del bosque nuboso, iii) Proteger los recursos hídricos que originan los ríos Guacimal en la vertiente Pacífica, y Chiquito, Caño Negro y Peñas Blancas, en la vertiente Caribe de la Cordillera de Tilarán, iv) Proporcionar espacios para la educación ambiental, los estudios técnicos y la investigación científica, v) Proteger los recursos paisajísticos sobresalientes de la reserva, vi) Proporcionar servicios y actividades recreativas 
y de turismo que favorezcan la conservación de los recursos naturales presentes en la reserva y vii) Contribuir con el desarrollo socioeconómico de las comunidades localizadas en el entorno de la reserva (zona de amortiguamiento).

Para efectos de lograr sus objetivos, la Reserva Monteverde cuenta con un equipo de trabajo de 40 personas, cuyas funciones están distribuidas según se muestran en la Figura 3. La mayor parte del personal de la Reserva Monteverde es de origen local (80\%). La administración se encarga de contratar personal capacitado y cuenta con un programa de incentivos para los funcionarios que deseen avanzar sus estudios formales con el fin de profesionalizar su planilla de trabajo.

La Reserva Monteverde brinda a la sociedad, además del servicio de proteger uno de los hábitats más frágiles del mundo, una serie de servicios ecosistémicos, dentro de los cuales uno de los más sobresalientes es la conservación de las nacientes de los principales ríos que alimentan el embalse Arenal en la Vertiente Caribe, donde se produce más del $50 \%$ de la electricidad del país. Además, realiza el trabajo de conservación en una forma amigable e inclusiva para la comunidad local brindando no solamente oportunidades de empleo directo sino que indirecto, ya que funciona como el atractivo central para el turismo de la región, principal fuente de ingresos para la población (Bermúdez y Hernández 2007).

\section{Metodología}

Para evaluar el nivel de sostenibilidad de la Reserva Monteverde, se realizó un proceso de análisis del entorno sobre el proyecto en cuanto a su historia y ubicación tanto geográfica como ecológica. También se investigó acerca del contexto al cual está circunscrita el área protegida y se llevó a cabo una revisión en cuanto al modelo de gestión. Las fuentes de información utilizadas en dicho trabajo se obtuvieron por medio de visitas al área protegida realizando entrevistas no estructuradas, así como, a través de la búsqueda de literatura tanto física como digital.

Por otra parte, con el fin de explicar el por qué ésta reserva ha sido un ejemplo exitoso de conservación y desarrollo sostenible, se llevó a cabo una evaluación del proyecto bajo las tres dimensiones teóricas de la sostenibilidad (ambiental, social, económica), a través de un análisis desagregado de indicadores empleando la metodología sobre Mapas Multicriterio, la cual tiene una amplia efectividad para evaluar la sostenibilidad en sistemas de manejo (Astier et al 2008). Bajo dicha metodología, se seleccionaron aquellos indicadores que representan una función crítica en la red de relaciones del sistema que se está evaluando (Tabla 1,2,3) (Astier et al 2008). Estos indicadores fueron incorporados en una matriz de resultados (de elaboración propia) en el programa Microsoft Excel, donde se efectuó la asignación de rangos y la respectiva

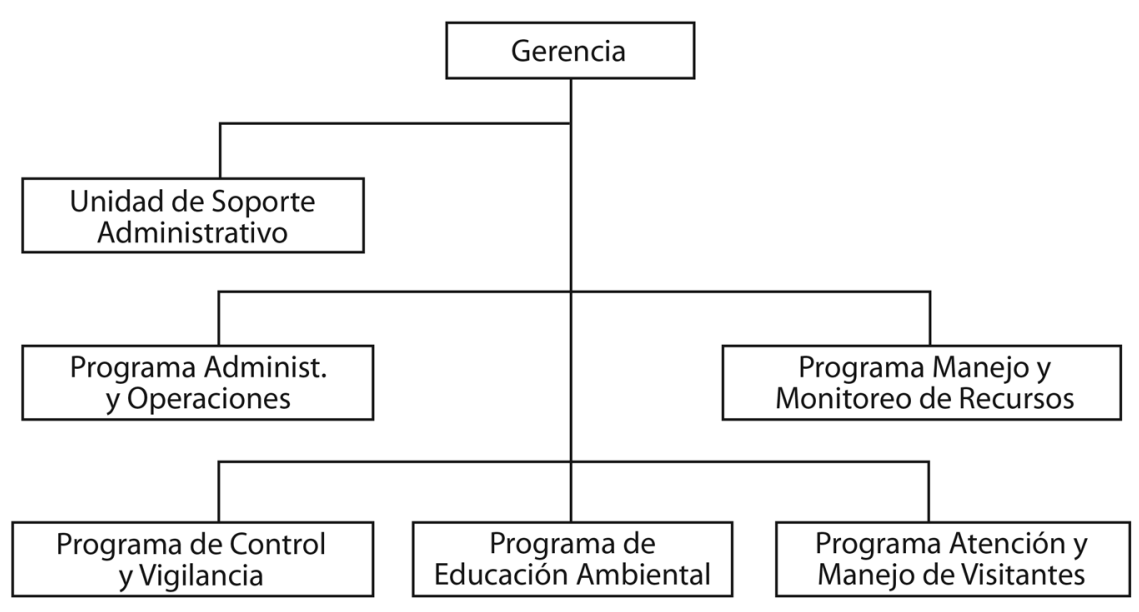

Figura 3. Organigrama del equipo de trabajo de la RBBNM. Fuente. Bermúdez y Hernández (2005). 
TABLA 1

Indicadores Ambientales. Mapa Multicriterio. Reserva Monteverde. Abril 2015.

\begin{tabular}{|c|c|c|}
\hline $\begin{array}{l}\text { Ámbito/ } \\
\text { Área Ambiental }\end{array}$ & Indicador & Descripción \\
\hline \multirow[t]{3}{*}{ Ecosistema } & $\begin{array}{l}\text { Vulnerabilidad del } \\
\text { ecosistema }\end{array}$ & $\begin{array}{l}\text { El ecosistema que se protege está amenazado y es vulnerable a la } \\
\text { extinción, entre más vulnerable sea mayor puntaje }\end{array}$ \\
\hline & Especies endémicas & $\begin{array}{l}\text { Se protegen especies endémicas, entre más especies endémicas } \\
\text { mayor puntaje }\end{array}$ \\
\hline & $\begin{array}{l}\text { Especies en peligro de } \\
\text { extinción }\end{array}$ & $\begin{array}{l}\text { Se protegen especies en peligro de extinción, entre mayor número } \\
\text { de especies en peligro mayor puntaje }\end{array}$ \\
\hline \multirow[t]{6}{*}{ Planificación } & Plan de manejo & $\begin{array}{l}\text { Cuenta con un plan de manejo del área protegida, entre más completo } \\
\text { sea el plan mayor puntaje }\end{array}$ \\
\hline & Plan de monitoreo & $\begin{array}{l}\text { Cuenta con un plan de monitoreo de los objetivos de manejo, entre más } \\
\text { competo sea el plan mayor puntaje }\end{array}$ \\
\hline & Capacidad de carga & $\begin{array}{l}\text { Cuenta con un plan de capacidad de carga que es respetado a cabalidad } \\
\text { para asegurar el no deterioro del ecosistema por la visitación, entre más } \\
\text { completo sea el plan y la utilización del sistema mayor puntaje }\end{array}$ \\
\hline & Conservación ex situ & $\begin{array}{l}\text { Realiza labores de conservación fuera del área protegida, entre mayor } \\
\text { sean las actividades de conservación a lo externo mayor puntaje }\end{array}$ \\
\hline & Protección y vigilancia & $\begin{array}{l}\text { Cuenta con un programa de protección y vigilancia de los recursos } \\
\text { naturales protegidos, entre más completo y efectivo sea el plan, } \\
\text { mayor puntaje }\end{array}$ \\
\hline & Investigación & $\begin{array}{l}\text { Cuenta con un programa de investigación que promueve el } \\
\text { conocimiento del ecosistema que se protege, entre más completo y } \\
\text { efectivo sea el plan mayor puntaje }\end{array}$ \\
\hline \multirow[t]{8}{*}{ Gestión } & Personal & $\begin{array}{l}\text { Cuenta con el personal suficiente y capacitado para realizar la protección } \\
\text { y manejo efectivo del área protegida, mayor puntaje cuando haya } \\
\text { personal suficiente y capacitado }\end{array}$ \\
\hline & $\begin{array}{l}\text { Gestión de desechos } \\
\text { sólidos }\end{array}$ & En su facilidades realiza una gestión eficiente de los desechos solidos \\
\hline & $\begin{array}{l}\text { Gestión de desechos } \\
\text { líquidos }\end{array}$ & $\begin{array}{l}\text { En su facilidades realiza una gestión eficiente de los desechos líquidos, } \\
\text { si cuenta con planta de tratamiento evaluada por el Ministerio de Salud } \\
\text { mayor puntaje }\end{array}$ \\
\hline & Manejo Emisiones GEI & $\begin{array}{l}\text { Posee un plan de mitigación de emisiones de carbono y otros gases de } \\
\text { efecto invernadero, entre más completo el plan mayor puntaje }\end{array}$ \\
\hline & $\begin{array}{l}\text { Adaptación al cambio } \\
\text { climático }\end{array}$ & $\begin{array}{l}\text { Posee un plan de adaptación con objetivos y metas al cambio climático, } \\
\text { entre más completo sea el plan mayor puntaje }\end{array}$ \\
\hline & Capacitación personal & $\begin{array}{l}\text { Cuenta con un programa de capacitación hacia sus empleados sobre } \\
\text { los objetivos y metas de conservación del área protegida, entre más } \\
\text { completo sea el plan, mayor puntaje }\end{array}$ \\
\hline & Participación en redes & $\begin{array}{l}\text { Es miembro de alguna red o conglomerado de reservas que coordinan y } \\
\text { compartes estrategias de manejo de áreas protegidas, mayor puntaje si } \\
\text { pertenece a grupos con trabajos afines }\end{array}$ \\
\hline & $\begin{array}{l}\text { Programas de } \\
\text { certificación }\end{array}$ & $\begin{array}{l}\text { Participa en programas de certificación como CST y Bandera Azul } \\
\text { ecológica, mayor puntaje si participa y mantiene las certificaciones }\end{array}$ \\
\hline Legislación & $\begin{array}{l}\text { Leyes y decretos } \\
\text { ambientales }\end{array}$ & $\begin{array}{l}\text { La reserva guía sus operaciones bajo el marco de las leyes de carácter } \\
\text { ambiental incluyendo pero no limitado a Ley biodiversidad, Ley Forestal, } \\
\text { Ley orgánica del ambiente. }\end{array}$ \\
\hline
\end{tabular}

Fuente. Elaboración del grupo de trabajo. 
TABLA 2

Indicadores Sociales. Mapa Multicriterio. Reserva Monteverde. Abril 2015.

\begin{tabular}{|c|c|c|}
\hline $\begin{array}{l}\text { Ámbito / } \\
\text { Área Social }\end{array}$ & Indicador & Descripción \\
\hline \multirow[t]{5}{*}{ Educación } & $\begin{array}{l}\text { Educación ambiental } \\
\text { visitantes }\end{array}$ & $\begin{array}{l}\text { Cuenta con un programa efectivo de educación ambiental hacia los } \\
\text { visitantes del área protegida, mayor puntaje si cuenta con el plan y } \\
\text { este es efectivo }\end{array}$ \\
\hline & $\begin{array}{l}\text { Educación ambiental } \\
\text { comunidad }\end{array}$ & $\begin{array}{l}\text { Cuenta con un programa de educación ambiental hacia los miembros } \\
\text { de la comunidad, mayor puntaje si cuenta con el plan y este es } \\
\text { efectivo }\end{array}$ \\
\hline & $\begin{array}{l}\text { Participación } \\
\text { estudiantes }\end{array}$ & $\begin{array}{l}\text { Promueve la participación de estudiantes en sus actividades, mayor } \\
\text { puntaje si los promueve }\end{array}$ \\
\hline & Participación comunal & $\begin{array}{l}\text { Involucra a la comunidad en sus actividades de conservación, mayor } \\
\text { puntaje si la involucra }\end{array}$ \\
\hline & Comunicación & $\begin{array}{l}\text { La información relevante generada por el programa de investigación } \\
\text { es transmitida a la comunidad y a los tomadores de decisiones, mayor } \\
\text { puntaje si lo realiza }\end{array}$ \\
\hline \multirow[t]{2}{*}{ Legislación } & $\begin{array}{l}\text { Leyes y decretos } \\
\text { operativos }\end{array}$ & $\begin{array}{l}\text { El área protegida cumple con las leyes y reglamentos vigentes en } \\
\text { cuanto al manejo del área protegida: Código de trabajo, Ley para } \\
\text { discapacitados, leyes municipales, ley de salud, mayor puntaje si la } \\
\text { respuesta es afirmativa }\end{array}$ \\
\hline & Plan de emergencias & $\begin{array}{l}\text { Cuenta con un plan de atención de emergencias y desastres naturales, } \\
\text { mayor puntaje entre más completo sea el plan }\end{array}$ \\
\hline \multirow[t]{5}{*}{$\begin{array}{l}\text { Beneficios directos } \\
\text { a la comunidad }\end{array}$} & Visitación local & $\begin{array}{l}\text { Permite que los miembros de la comunidad visite el área protegida sin } \\
\text { costo, mayor puntaje si lo permite }\end{array}$ \\
\hline & Personal local & $\begin{array}{l}\text { Emplea más de un } 50 \% \text { de personas de la comunidad local, mayor } \\
\text { puntaje si lo hace }\end{array}$ \\
\hline & Tarifas preferenciales & $\begin{array}{l}\text { Posee un esquema de tarifas preferenciales para estudiantes, } \\
\text { discapacitados y adultos mayores, mayor puntaje si lo hace }\end{array}$ \\
\hline & Responsabilidad social & $\begin{array}{l}\text { Cuenta con un programa de responsabilidad social debidamente } \\
\text { financiado con objetivos claros, mayor puntaje entre mejor sea el plan }\end{array}$ \\
\hline & Incidencia política & $\begin{array}{l}\text { Participa activamente en actividades de incidencia política para } \\
\text { propiciar un desarrollo sostenible en su entorno, mayor puntaje si lo } \\
\text { realiza }\end{array}$ \\
\hline \multirow[t]{2}{*}{ Encadenamientos } & $\begin{array}{l}\text { Encadenamiento con } \\
\text { negocios locales }\end{array}$ & $\begin{array}{l}\text { El área protegida promueve la generación de encadenamientos } \\
\text { productivos de bienes y servicios a nivel local, mayor puntaje si lo } \\
\text { promueve }\end{array}$ \\
\hline & $\begin{array}{l}\text { Encadenamiento con } \\
\text { negocios nacionales }\end{array}$ & $\begin{array}{l}\text { El área protegida promueve la generación de encadenamientos } \\
\text { productivos de bienes y servicios a nivel nacional, mayor puntaje si lo } \\
\text { promueve }\end{array}$ \\
\hline
\end{tabular}

Fuente. Elaboración del grupo de trabajo.

ponderación de cada indicador con el fin de implementar la evaluación y el posterior análisis de los datos.

Para efectos de llevar a cabo la evaluación de la sostenibilidad de la Reserva Monteverde a través de la valoración de los indicadores seleccionados, se realizó una visita al área protegida donde se hizo una entrevista con el equipo administrativo (gerencia general, directora de investigación, director de mantenimiento) por medio de la cual se valoró cada uno de los indicadores según la información compartida por 
TABLA 3

Indicadores Económicos. Mapa Multicriterio. Reserva Monteverde. Abril 2015.

\begin{tabular}{|c|c|c|}
\hline $\begin{array}{l}\text { Ámbito/Área } \\
\text { Económico }\end{array}$ & Indicador & Descripción \\
\hline \multirow[t]{3}{*}{ Fuentes de ingresos } & Generación de recursos & $\begin{array}{l}\text { Genera recursos suficientes para garantizar la conservación del área } \\
\text { protegida, mayor puntaje si los genera }\end{array}$ \\
\hline & $\begin{array}{l}\text { Diversificación fuentes } \\
\text { de ingresos }\end{array}$ & $\begin{array}{l}\text { Cuenta con una variedad en la fuente de recursos que financien la } \\
\text { operación, entre más fuentes más puntaje }\end{array}$ \\
\hline & Riesgo en ingresos & $\begin{array}{l}\text { Nivel de riesgo en la principales fuentes de ingresos, entre más alto } \\
\text { sea el riesgo, más bajo el puntaje. }\end{array}$ \\
\hline \multirow[t]{3}{*}{$\begin{array}{l}\text { Gestión efectiva de } \\
\text { recursos }\end{array}$} & Inversión de recursos & $\begin{array}{l}\text { Más de un } 75 \% \text { de los recursos generados son invertidos en el } \\
\text { manejo del área protegida, a mayor porcentaje mayor puntaje }\end{array}$ \\
\hline & Costo/Beneficio & $\begin{array}{l}\text { La relación Costo/Beneficio es positiva, mayor puntaje entre mejor } \\
\text { sea la relación }\end{array}$ \\
\hline & Endeudamiento & $\begin{array}{l}\text { El nivel de endeudamiento está por debajo de } 10 \% \text { del presupuesto } \\
\text { anual operativo, entre menos el endeudamiento mayor puntaje }\end{array}$ \\
\hline \multirow[t]{2}{*}{ Gestión del riesgo } & Fideicomisos & $\begin{array}{l}\text { Cuenta con un fideicomiso o plan de emergencia financiera que le } \\
\text { permita asegurar la protección de la Reserva en caso que las fuentes } \\
\text { de ingresos se minimicen, mayor punta si cuenta con el plan y si } \\
\text { asegura a perpetuidad la protección del área protegida }\end{array}$ \\
\hline & Planes de contingencia & $\begin{array}{l}\text { Cuenta con planes de contingencia en caso que las fuentes de } \\
\text { ingresos sufran deterioro, entre mejor y más completos sean los } \\
\text { planes mayor puntaje }\end{array}$ \\
\hline
\end{tabular}

Fuente. Elaboración del grupo de trabajo.

el equipo gerencial. También, se llevó a cabo una inspección del área para efectos de comprobar la veracidad de la información proporcionada.

Cabe resaltar que los puntajes asignados en la matriz de resultados reflejan el criterio de los evaluadores de acuerdo a la información proporcionada por el equipo administrativo. Una vez ejecutada la evaluación, se procedió a realizar el análisis e interpretación de los datos utilizado el programa Microsoft Excel. A partir de los resultados obtenidos se derivaron las conclusiones y recomendaciones del estudio de caso. Es importante mencionar que esta investigación se delimita como una primera etapa al análisis interno de la Reserva Biológica Bosque Nuboso Monteverde, dejando pendiente el factor externo de la comunidad circunvecina.

\section{Resultados y discusión}

A continuación, se presentan los resultados de la evaluación en forma desagregada por ámbito de análisis.

\section{Ámbito Ambiental}

La Reserva Monteverde no solamente cumple la función de prestar el servicio de protección de uno de los ecosistemas más frágiles del mundo, donde se conservan especies endémicas, vulnerables y en peligro de extinción como lo son los Aguacatillos (Familia Lauraceae), el Quetzal (Pharomacros moccino) y el Pájaro Campana (Procnias tricarunculata), sino no que lo realiza en una forma planificada, bajo un modelo de gestión eficiente y cumpliendo 
TABLA 4

Resultados de la evaluación en el ámbito ambiental de la sostenibilidad.

Reserva Biológica Bosque Nuboso Monteverde. Abril 2015.

\begin{tabular}{lcccc}
\multicolumn{1}{c}{ Ámbito Ambiente } & Puntaje máximo & Puntaje máximo\% & Puntaje Obtenido & Puntaje Obtenido \% \\
Ecosistema & 30 & 100 & 30 & 100 \\
Planificación & 60 & 100 & 60 & 100 \\
Gestión & 80 & 100 & 70 & 87.5 \\
Legislación & 10 & 100 & 10 & 100 \\
\hline
\end{tabular}

Fuente. Elaboración del grupo de trabajo.

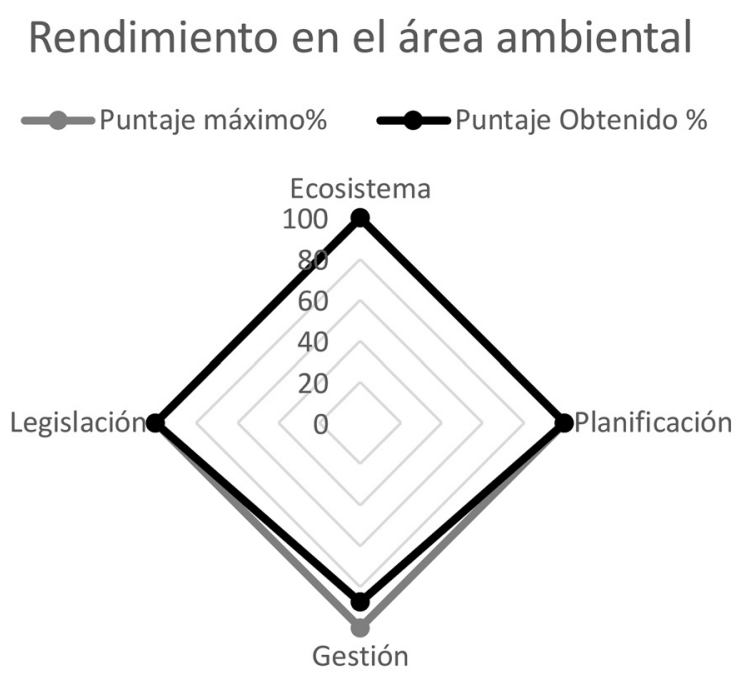

Figura 4. Resultados de la evaluación en el ámbito ambiental de la sostenibilidad. Reserva Biológica Bosque Nuboso Monteverde. Abril 2015. Fuente. Elaboración del grupo de trabajo.

con la legislación vigente en la temática ambiental (Tabla 4 y Figura 4).

Uno de los elementos de éxito de la Reserva Monteverde es la adecuada planificación que realiza su equipo administrativo. Bajo este rubro, la administración del área protegida se ha especializado en llevar a cabo todas sus operaciones siguiendo las líneas de un plan estratégico que ha sido diseñado en función de los objetivos planteados. Esta planificación les permite llevar un mejor control en el logro de sus metas y les da la ventaja de adaptar su operación en épocas de crisis económicas externas.

Desde el punto de vista específico de impactos al ambiente, la reserva ha desarrollado una serie de mecanismos para identificar los impactos negativos que el área produce lo cual le ha permito desarrollar medidas para la mitigación en forma efectiva. Por ejemplo, para efectos de controlar todos los impactos que el área protegida puede generar por la visitación de turistas, el área se encuentra debidamente zonificada en dos segmentos: el área de uso público que comprende solamente el $3 \%$ del terreno, y el área de uso restringido que acapara el 97\% restante, donde las únicas actividades que se permiten son la investigación y la entrada de grupos organizadas de estudiantes y naturalistas.

La visitación turística es manejada a través de un mecanismo de gestión de la capacidad de carga, mediante el cual se distribuye diariamente y en forma estratégica la cantidad de visitantes dentro del área de uso público (Figura 5) para reducir el impacto por sobrecarga. Asimismo, en el área de acceso público, la cual está provista de infraestructura para recibir diariamente 450 personas, la reserva cuenta con sistemas para favorecer el reciclaje de desechos sólidos (Figura 6) y para disponer adecuadamente de los desechos líquidos a través de un sistema moderno de tratamiento de aguas residuales (Figura 7). De igual manera, se promueve el ahorro de la energía a través del uso de dispositivos inteligentes, como los calentadores de agua solar instalados sobre el techo del albergue (Figura 8). Además, la reserva cuenta con un programa de protección y vigilancia de los recursos naturales con personal altamente capacitado a nivel técnico, legal y en manejo de conflictos, los cuales se encargan de vigilar que no haya cacería, tala ilegal o que se cometa cualquier otro tipo de delito ambiental dentro de los límites del área natural. 


\section{䁬 Mapa de Senderos | Trails map}
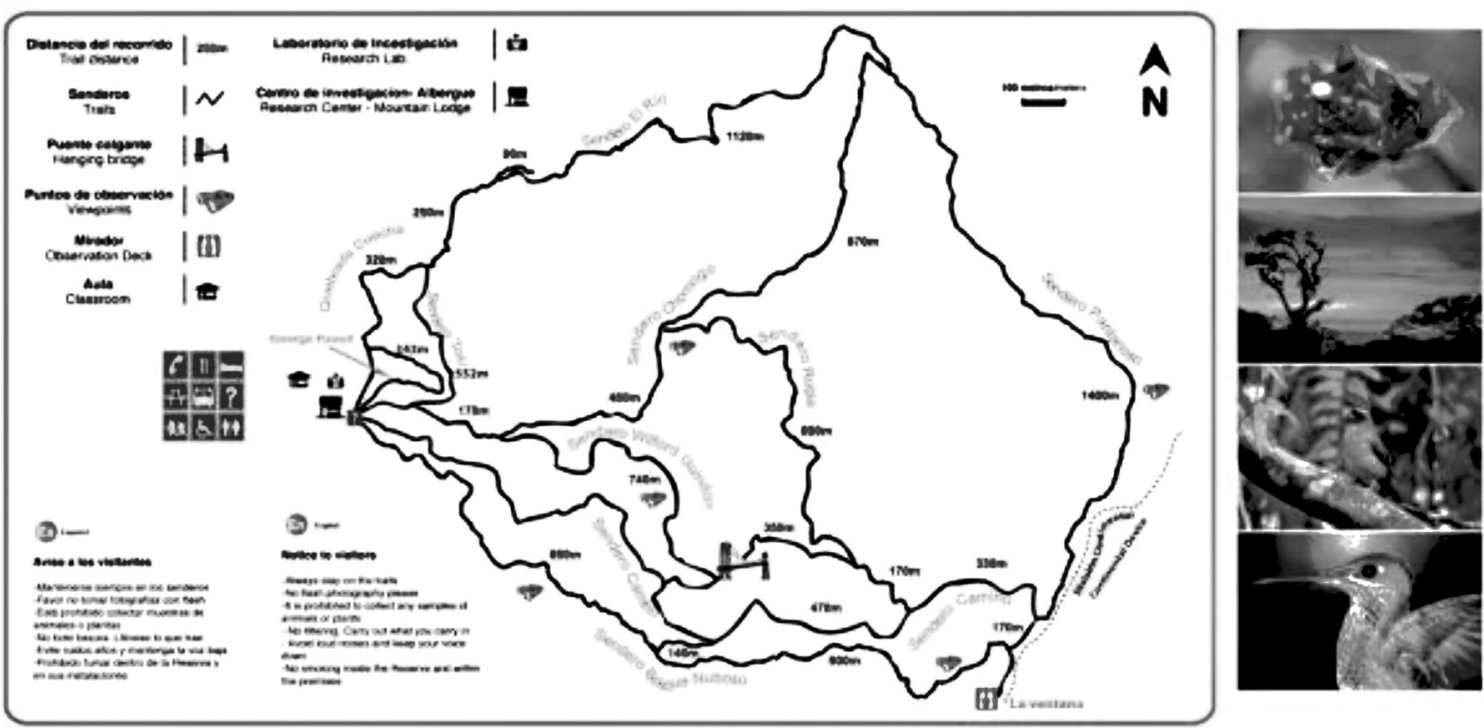

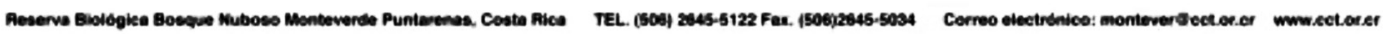

Figura 5. Mapa de senderos de la zona de uso público de la reserva donde se distribuye la visitación diaria. Abril 2015. Fuente. Reserva Biológica Bosque Nuboso Monteverde 2015.

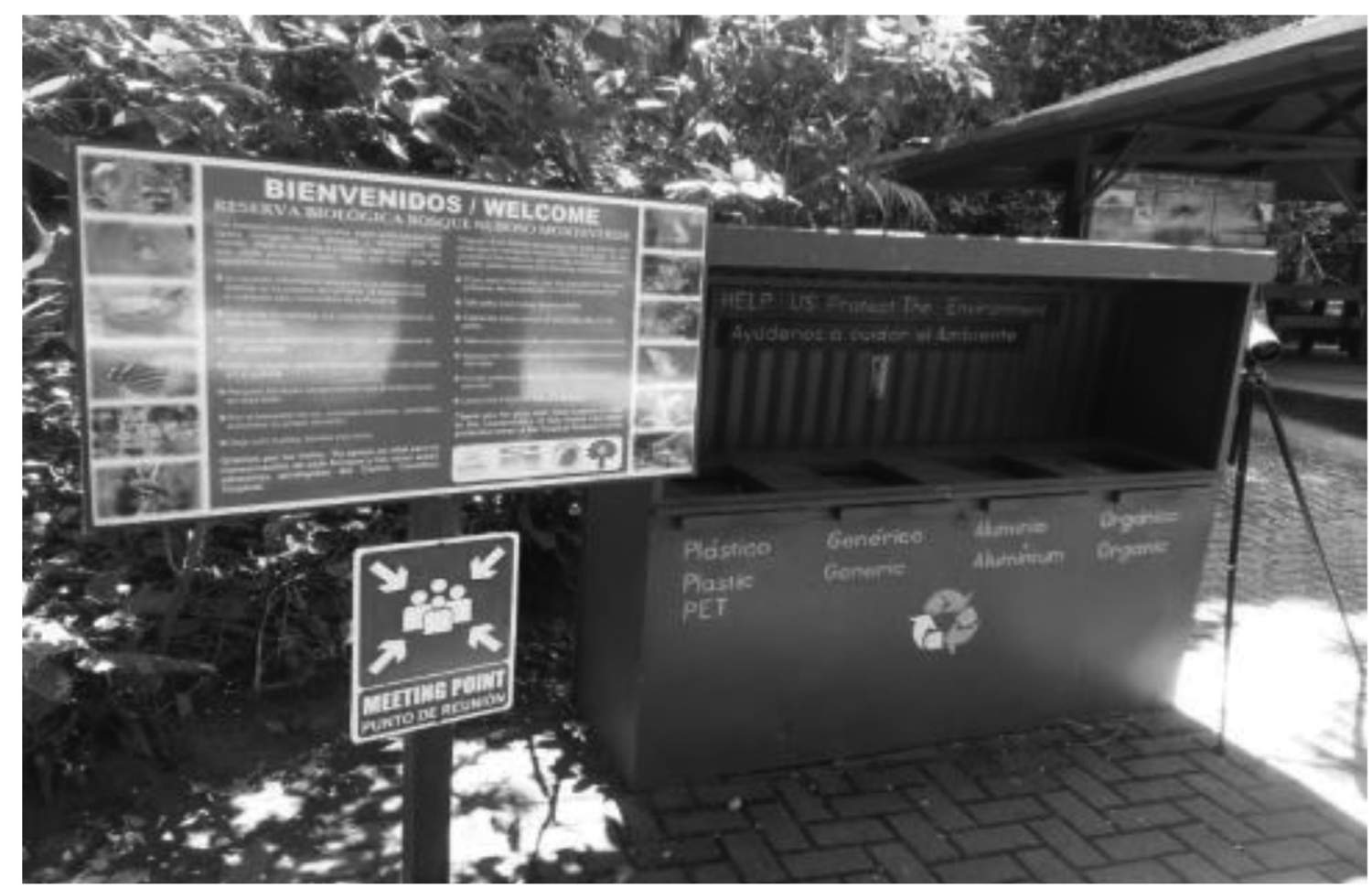

Figura 6. Sistema para favorecer el reciclaje de desechos sólidos por parte de los usuarios de la Reserva Monteverde. Fuente. Fotografía tomada por Fabricio Camacho. Abril 2015. 


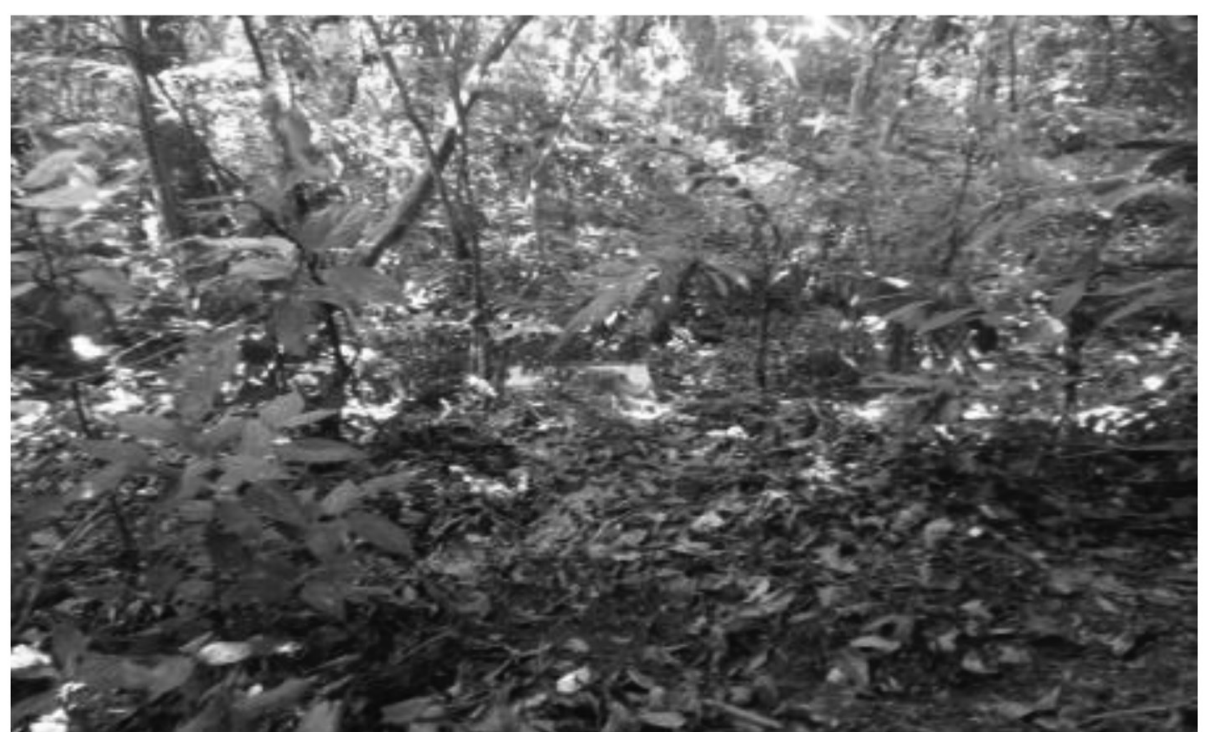

Figura 7. Planta de tratamiento de desechos líquidos provenientes de la cafetería, albergue y baños públicos. Reserva Monteverde. Nótese que no se puede identificar ningún tipo de afectación al ecosistema donde se encuentra la planta de tratamiento. La misma cumple con los parámetros vigentes de vertidos determinados por la legislación Costarricense. Fuente. Fotografía realizada por Fabricio Camacho. Abril 2015.

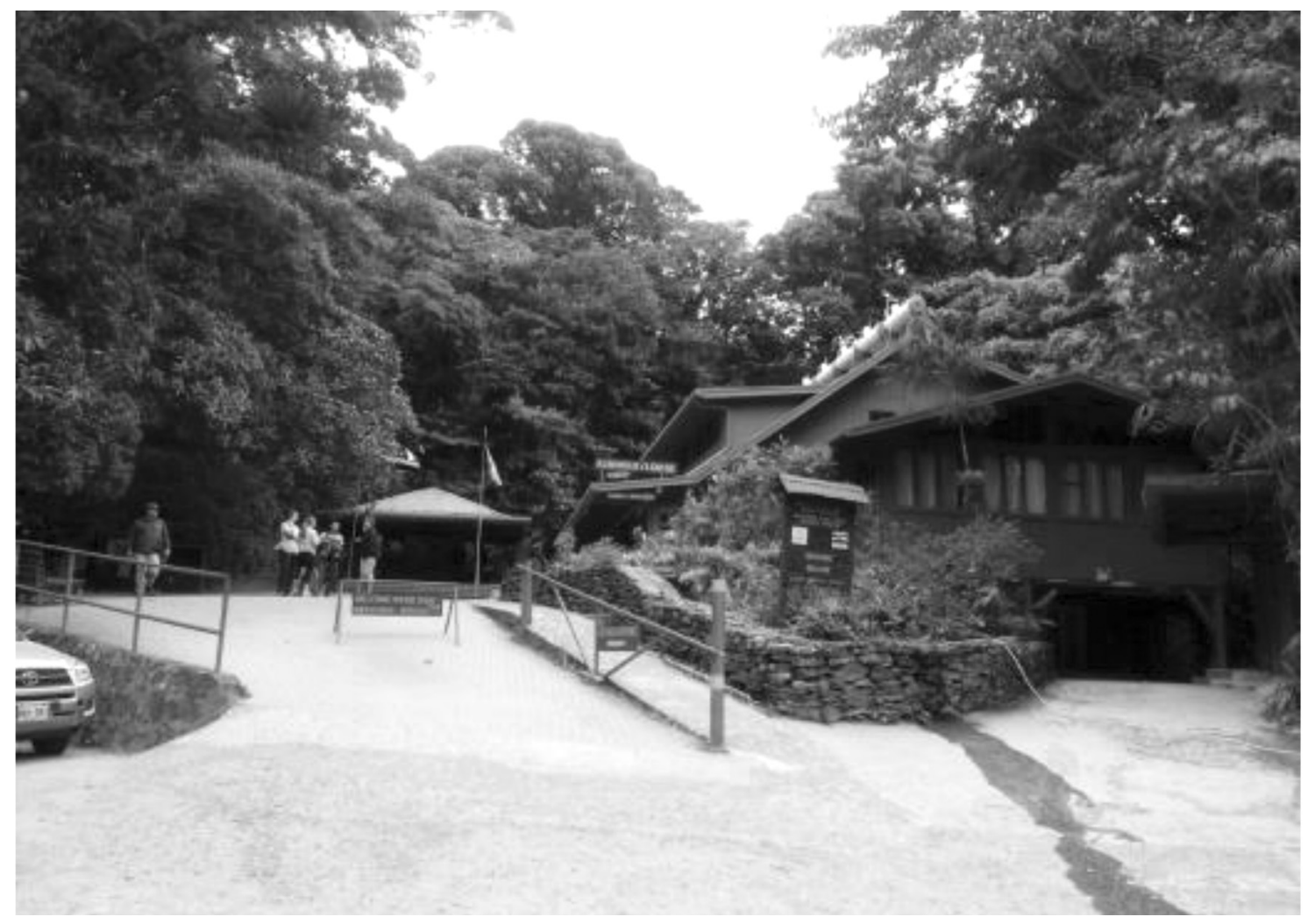

Figura 8. Instalaciones de acceso a la Reserva Monteverde. La arquitectura de las instalaciones está integrada al paisaje. Fuente. Fotografía realizada por Fabricio Camacho. Abril 2015. 
Es importante destacar que dentro los elementos de interacción con la comunidad, la Reserva también promueve que sus funcionarios reciclen en sus casas y cuenta con un plan de incentivos para los colaboradores que lleven su material de reciclaje al centro de acopio del área protegida. Los recipientes son a prueba de animales para que estos no pierdan sus ciclos naturales por alimentación artificial. Se educa a los visitantes de no alimentar a la fauna, dejar basura ni extraer plantas o animales.

Por otra parte, la Reserva Monteverde cuenta con un programa de investigación y monitoreo de los recursos naturales, cuya principal función es la de generar información valiosa en cuanto al ecosistema para la mejor toma de decisiones por parte de la administración. De este programa se desprende la información técnica que los administradores del área necesitan para llevar a cabo su trabajo, el cual en muchas instancias sobrepasa los límites del área protegida, ya que promueven iniciativas de conservación a lo externo del área natural como lo es, por ejemplo, la concepción del Corredor Biológico Pájaro Campana, proceso que fue liderado por la Reserva Monteverde desde 1990 y que logró consolidarse en el año 2007.

En otro sentido, cabe destacar que la Reserva Monteverde no se guarda la información que genera en cuanto a los resultados de su gestión. Por el contrario, la administración está en constante participación e interacción con otras áreas protegidas tanto públicas como privadas a nivel local, nacional e internacional. De esta forma, la reserva participa activamente en la Red de Reservas Privadas de Costa Rica, atiende solicitudes del Sistema de Parques Nacionales de Costa Rica y participa en foros y congresos relacionados al manejo de áreas silvestres protegidas a nivel latinoamericano. Asimismo, es importante hacer mención que la reserva se encuentra oficialmente certificada por el programa de Sostenibilidad Turística de Costa Rica, así como por el programa Bandera Azul Ecológica. Ambas plataformas le otorgan al área natural un reconocimiento importante por la labor realizada en cuanto a la sostenibilidad y protección de las comunidades y el medio ambiente.
Existen dos elementos ambientales en los que el equipo administrativo reconoce que deben mejorar. El primero de ellos es el desarrollar un plan de manejo de emisiones de gases de efecto invernadero (GEI) y el segundo es también desarrollar un plan de adaptación al cambio climático. Con respecto al primero, la administración indica que actualmente se realizan actividades aisladas de mitigación como son la siembra de árboles en el Corredor Biológico Pájaro Campana, actividades de conservación y educación ambiental dirigidas tanto al personal como a la comunidad. Sin embargo, no se han realizado los estudios respectivos para conocer en detalle la huella de carbono equivalente de la operación y por ende no existe un plan consolidado de gestión de emisiones.

En ese sentido, los autores de la evaluación estiman que aunque sí es necesario contar con la valoración de emisiones y su respectivo plan de mitigación, debido a la gran cantidad de carbono almacenado en la reserva, este podría ser un mecanismo no solo para mitigar las propias emisiones, sino que podría representar una oportunidad para fortalecer y diversificar las fuentes de ingresos del área protegida a través de la incorporación de la reserva como un área de almacenamiento de carbono por lo cual se podría obtener créditos económicos.

Por su parte, con respecto al plan de adaptación a la variabilidad climática, es imperativo que la administración comience a realizar los estudios respectivos y generar los escenarios para conocer los efectos potenciales de dicha variabilidad sobre los objetivos de conservación actuales, considerando que el bosque nuboso es uno de los ecosistemas más vulnerables a este fenómeno. En ese sentido, se considera que aunque actualmente se realicen acciones indirectas y aisladas de adaptación en cuanto al funcionamiento de la planta física del proyecto, es importante entender los cambios potenciales que podrían ocurrir a nivel del ecosistema y determinar los grados de afectación de índole ambiental, social y económica, para así poder planear las actividades que promuevan la adaptación del sistema de gestión hacia uno más resiliente al cambio climático. 
TABLA 5

Resultados de la evaluación en el ámbito social de la sostenibilidad.

Reserva Biológica Bosque Nuboso Monteverde. Abril 2015.

\begin{tabular}{lcccc}
\multicolumn{1}{c}{ Ámbito Social } & Puntaje máximo & Puntaje máximo\% & Puntaje Obtenido & Puntaje Obtenido \% \\
Educación & 50 & 100 & 50 & 100 \\
Legislación & 20 & 100 & 20 & 100 \\
Beneficios directos a la & 50 & 100 & 46 & 92 \\
comunidad & 20 & 100 & 20 & 100 \\
Encadenamientos & &
\end{tabular}

Fuente. Elaboración del grupo de trabajo.

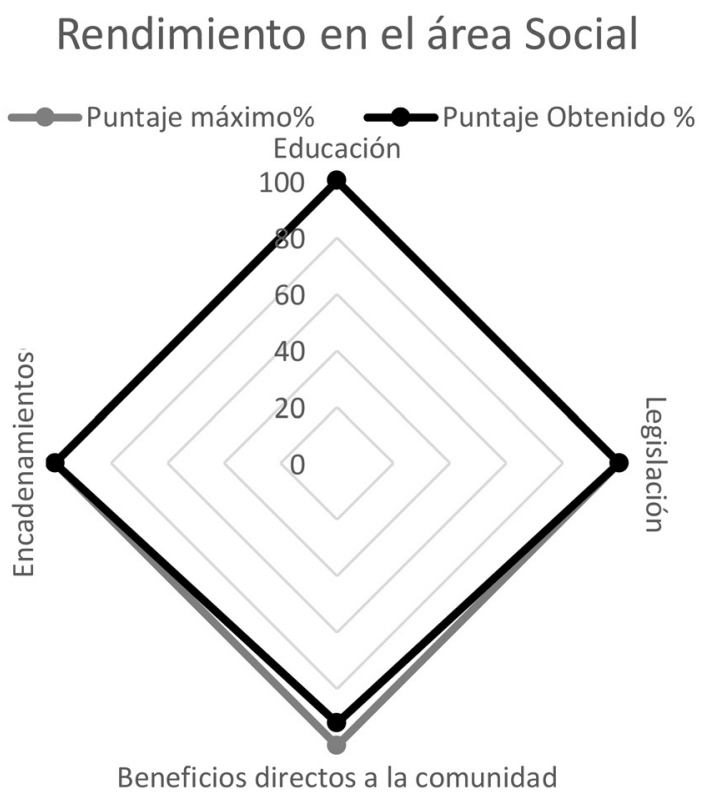

Figura 9. Resultados de la evaluación en el ámbito social de la sostenibilidad. Reserva Biológica Bosque Nuboso Monteverde. Abril 2015. Fuente. Elaboración del grupo de trabajo.

\section{Ámbito Social}

La Reserva Monteverde ha logrado interiorizar efectivamente el papel de ser un actor social responsable tanto a lo interno como a lo externo de su operación debido a que desde sus inicios, el proyecto fue establecido con la visión de funcionar no solo como un área de protección de los recursos naturales, sino que también como un centro dinámico de educación, sensibilización y transformación social (Tabla 5 y Figura 9). Dentro de éste ámbito, uno de los elementos más evidentes del compromiso social del proyecto son los esfuerzos de educación ambiental que la reserva realiza tanto con los visitantes como con las comunidades aledañas al área natural (Figura 10).

En ese sentido, dichos esfuerzos no se realizan en forma aislada sino que están profundamente integrados con los objetivos de conservación del área protegida para lo cual, por un lado, la reserva cuenta con un grupo de naturalistas capacitados, quienes son los responsables de transmitir el conocimiento a los visitantes, y por otro, también cuenta con personal que realiza labores de educación ambiental en las escuelas del distrito de Monteverde y que participa como uno de los principales gestores e iniciadores de la Comisión de Educación Ambiental de Monteverde (CEAM, http://ceamonteverde. weebly.com).

A través de la CEAM se organizan actividades que inciden sobre los diferentes segmentos de la población local. De esta forma, es en gran medida, que las actividades de la Reserva Monteverde han logrado establecer una cultura conservacionista en la zona de Monteverde, donde una amplia cantidad de ciudadanos son sensibles a la problemática ambiental y realizan esfuerzos auténticos para proteger el ambiente. De igual manera, la Reserva, desde sus orígenes, ha sido una de las principales fuentes generadoras de todo un movimiento social que ha atraído no solamente investigadores y conservacionistas, sino que a una gran diversidad de actores sociales como educadores, políticos, artistas y escritores que han hecho de esta zona un conglomerado intelectual con una visión común de conservación. 


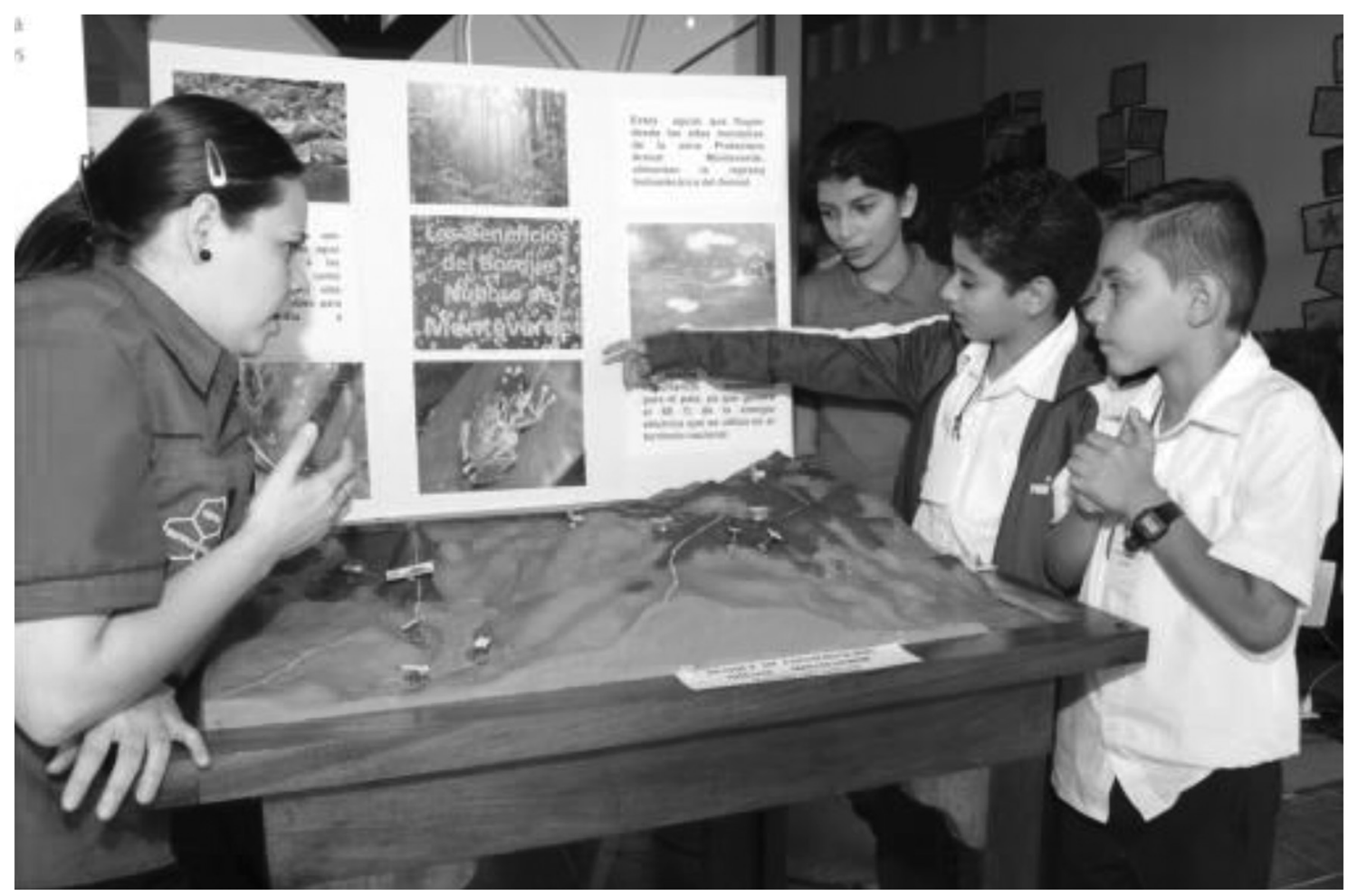

Figura 10. Bióloga y Directora del Programa de Investigación, Yoryineth Méndez, impartiendo charla a estudiantes sobre los beneficios del Bosque Nuboso. Programa de Educación Ambiental. Reserva Monteverde. Fuente. Fotografía realizada por Fabricio Camacho. Abril 2015.

Aunado a eso, la Reserva también ha fungido como un imán para el turismo, actividad que se ha convertido en la principal fuente generadora de empleo y dinamismo económico en la región promoviendo no solamente 40 puestos de trabajo, de los cuales más del $80 \%$ están ocupados por miembros de la comunidad local, sino que también potenciando todo un proceso de encadenamientos productivos, tanto a nivel local como regional, a través de la promoción del consumo de bienes y servicios por parte de los visitantes del área (Figura 11).

Por su parte, la reserva también posee una línea dentro su presupuesto para realizar aportes financieros y en especie para el desarrollo de la comunidad, donde como producto de este proceso se han realizado obras de infraestructura a nivel comunitario y se ha participado en proyectos de carácter social. En este ámbito, uno de los proyectos más sobresalientes de interés social que se financió fue la conformación de la
Sociedad de Artesanas Ecobambú, donde se le brindaron los recursos financieros y la asistencia técnica a un grupo de mujeres, amas de casa, en la comunidad de San Luis de Monteverde, para establecer un centro de producción de artesanías a partir del papel reciclado que se genera en la Reserva. En este centro, una vez transformado el papel en productos elaborados por las artesanas, es vendido al turismo en varios puntos de venta incluyendo en la tienda de regalos de la misma Reserva (Figura 12).

Paralelamente, otro proyecto interesante que realiza la reserva en función de incidir positivamente en el desarrollo social de la zona es a través de la asistencia técnica que el personal del área brinda a las escuelas selectas del distrito para que éstas logren obtener y mantener el programa de Bandera Azul Ecológica. En ese sentido, la reserva, a través de su programa de educación ambiental en las escuelas, brinda el acompañamiento para que tanto los docentes 


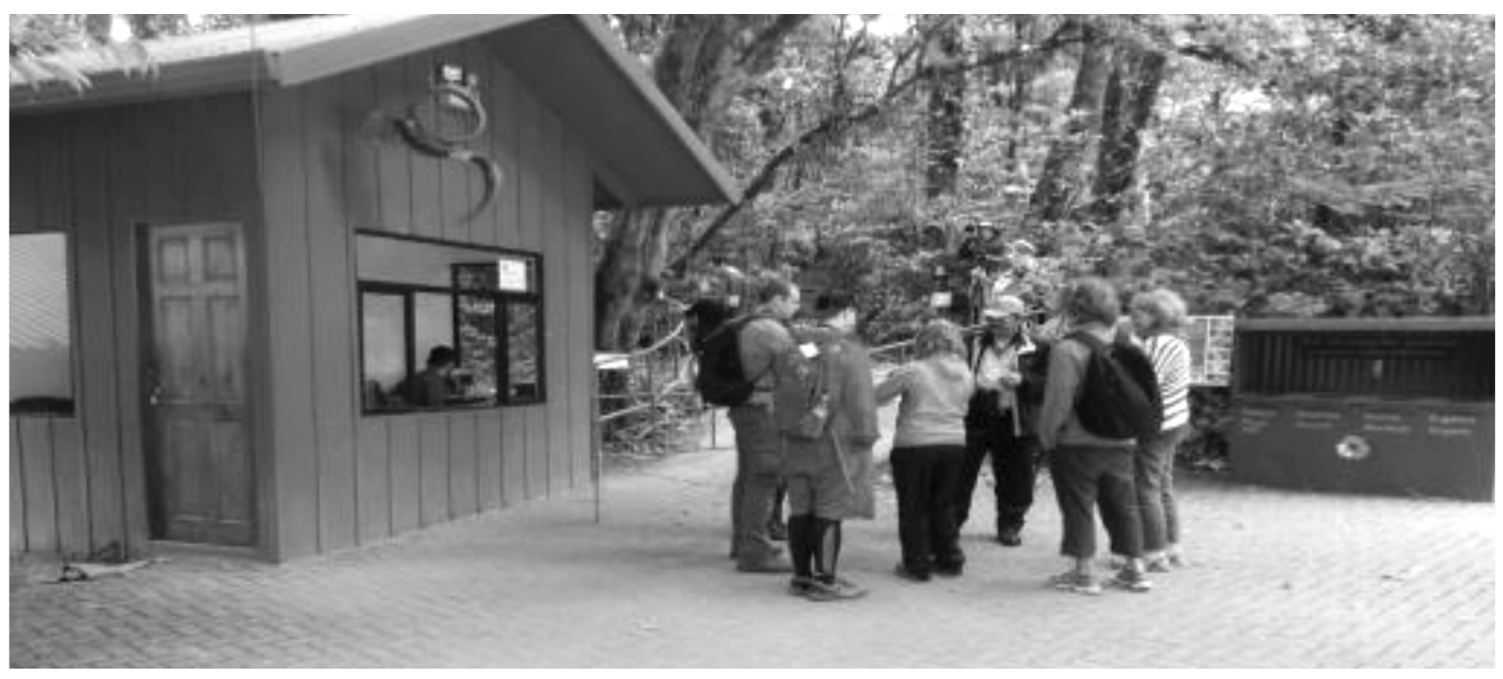

Figura 11. La Reserva Monteverde pone a disposición el área de uso público para que más de 25 guías locales brinden sus servicios a los visitantes de la zona. Fuente. Fotografía realizada por Fabricio Camacho. Abril 2015.
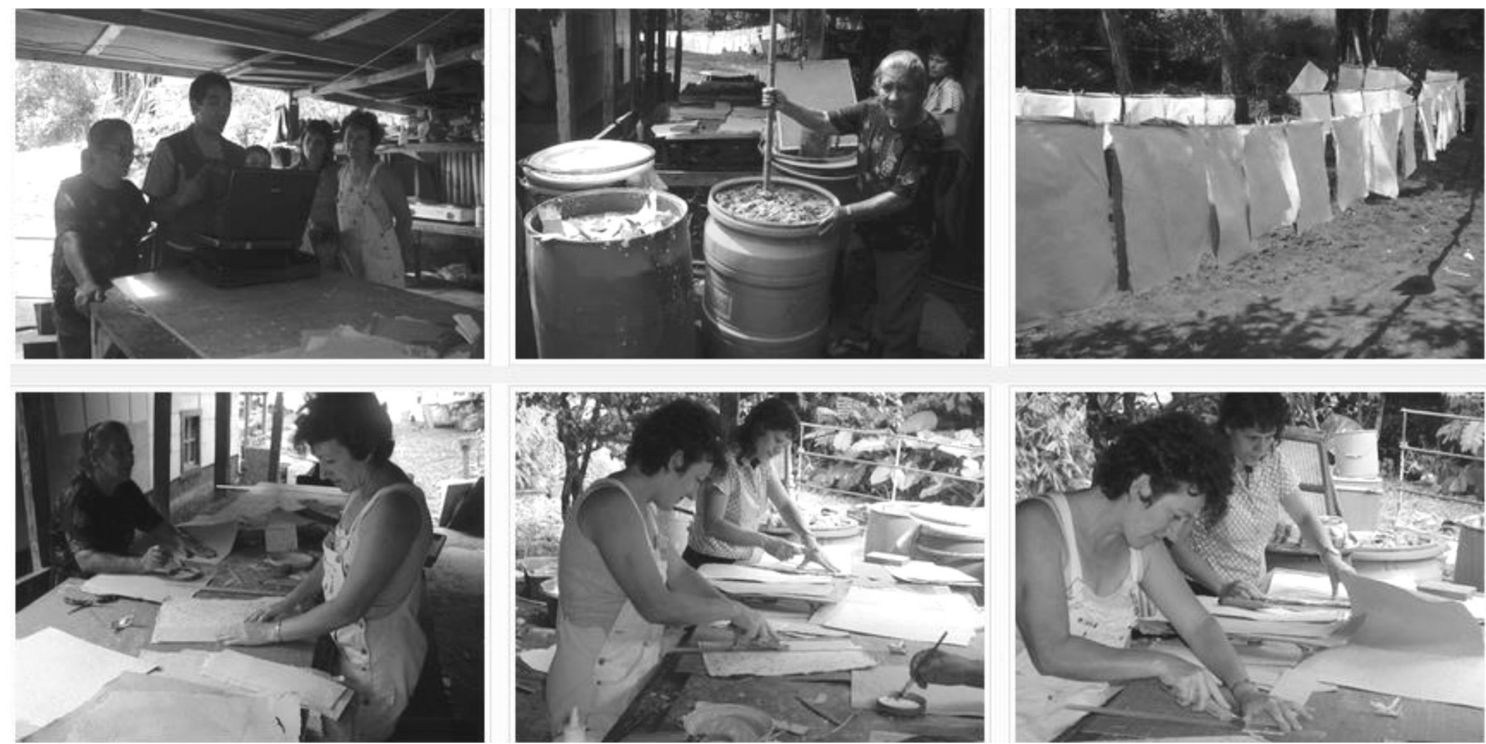

Figura 12. Asociación de Artesanas Ecobambú. Proyecto de producción de artesanía a partir de papel reciclado que fue financiado a través del programa de responsabilidad social de la Reserva Monteverde. Fuente. Fotografías realizadas por Fabricio Camacho. Abril 2015.

como los estudiantes desarrollen los procesos necesarios para formar parte de dicho programa.

Finalmente, uno de los elementos que debe considerar la administración de la Reserva Monteverde en el ámbito social, es el de desarrollar planes para incidir en el desarrollo de la región, más allá del programa de educación ambiental. Lo anterior para que la población local no pierda la noción que el turismo es un medio económico que debe manejarse cuidadosamente para que no termine causando más impactos que los que el ecosistema y la población pueda asimilar. Esto en vista que en los últimos 20 años, el desarrollo turístico fuera del área protegida, ha crecido exponencialmente y de forma no planificada, gracias a que muchos empresarios, a nivel local y nacional, han explotado el potencial turístico de la región y lo han aprovechado 
por medio del desarrollo de infraestructura a través de la cual se brindan servicios de diferente índole (p.ej. puentes colgantes, parques temáticos, tirolinas, hoteles, bares, restaurantes).

En ese sentido, Monteverde como región, se ha convertido en un destino turístico diversificado aparentemente sostenible. Empero, muchos empresarios no son conscientes de la historia de la región y no les ha importado la fragilidad del ecosistema y de la población. Algunos de estos empresarios se han enfocado exclusivamente en la explotación comercial, hecho que ha favorecido que algunos de ellos hayan terminado desarrollando proyectos que no van de acuerdo a la cultura conservacionista de la zona, poniendo en riesgo la idiosincrasia de la población y causando impactos ambientales y sociales difíciles de controlar para las autoridades locales y los miembros de la comunidad conservacionista.

Otro efecto social adherido al desarrollo turístico no planificado fuera del área protegida, ha sido la inmigración de personas de otras localidades e inclusive de otros países vecinos a la región. Estas personas han llegado a Monteverde en busca de empleo y mejores oportunidades para sus familias. Sin embargo, aunque una minoría ha logrado establecerse y mejorar su calidad de vida, otras lamentablemente han sido explotadas tanto en procesos de construcción como operación de los proyectos.

Algunas familias inmigrantes se han ubicado en áreas marginales de la región no aptas para vivienda, causando un desarrollo urbano no planificado principalmente en el sector de Cerro Plano y Santa Elena, bajo cementerio y los Llanos, hecho que ha provocado una fuerte presión sobre los recursos naturales como el agua y el ambiente en general que no ha podido ser manejada por la lenta capacidad de respuesta de algunas de las instituciones gubernamentales. Igualmente, el desarrollo explosivo de la zona y el crecimiento poblacional, también ha atraído una fuerte influencia de problemas sociales en la zona como lo son la inseguridad ciudadana y el desinterés por la comunidad, y de similar forma, las autoridades han sido incapaces de controlar esos procesos, lo cual pone en riesgo evidente el futuro de la región.

De esa forma, aunque la Reserva Monteverde tenga un amplio compromiso social y no sea el ente responsable de que haya ocurrido un proceso de desarrollo expansivo fuera de sus límites, la administración tiene la autoridad moral para hacer un fuerte llamado a la ciudadanía, así como a los empresarios, al gobierno local y otras entidades gubernamentales de la región para que estos desarrollen planes de desarrollo fundamentados en el hecho que Monteverde es un ecosistema muy frágil, con una población muy sensible que no pueden ser sobreexplotados a como ha ocurrido en otras regiones del país. Estos planes deben considerar que los efectos de un turismo masivo y el desarrollo urbano no planificado son contraproducentes tanto para el ambiente, como para el futuro de la economía y la integridad de la sociedad, hecho que ha sido evidente en otros destinos turísticos del país.

\section{Ámbito Económico}

A pesar de ser un proyecto de conservación, manejado por una organización de carácter científico con una fuerte proyección hacia la sociedad, la Reserva Monteverde opera como una empresa altamente eficiente en el manejo de sus recursos (Tabla 6, Figura 13). Bajo este esquema de gestión administrativo, la reserva

TABLA 6

\section{Resultados de la evaluación en el ámbito económico de la sostenibilidad. Reserva Biológica Bosque Nuboso Monteverde.}

\begin{tabular}{lcccc}
\multicolumn{1}{c}{ Ámbito Económico } & Puntaje máximo & Puntaje máximo\% & Puntaje Obtenido & Puntaje Obtenido \% \\
Fuentes de ingresos & 30 & 100 & 27 & 90 \\
Manejo efectivo recursos & 30 & 100 & 30 & 100 \\
Manejo del riesgo & 20 & 100 & 18 & 90 \\
\hline
\end{tabular}

Fuente. Elaboración del grupo de trabajo. 


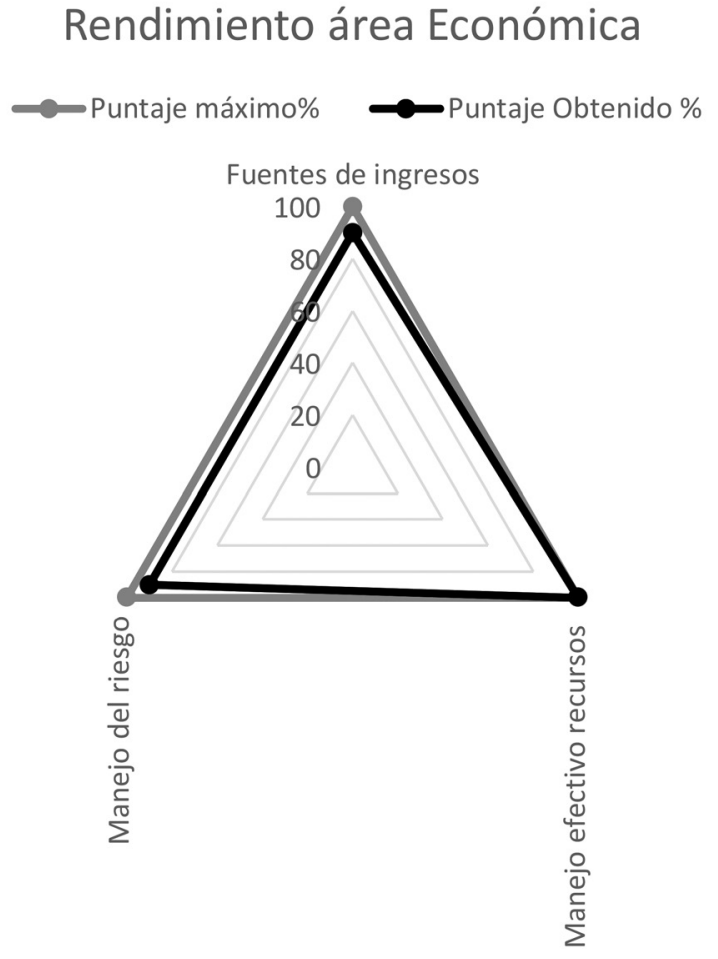

Figura 13. Resultados de la evaluación en el ámbito social de la sostenibilidad. Reserva Biológica Bosque Nuboso Monteverde. Fuente. Elaboración del grupo de trabajo.

realiza un control minucioso de los recursos generados, logrando un manejo efectivo del capital financiero producido, lo cual se refleja en una relación de costo/beneficio positiva y estable a través del tiempo. Cabe resaltar que el nivel de endeudamiento de la Reserva es nulo y que más del $75 \%$ del capital generado es reinvertido en el manejo de la operación, mientras que el $25 \%$ restante se distribuye en otros rubros de administración del CCT, incluyendo el mantenimiento y la operación de la sede central, así como de las otras reservas de la red de áreas protegidas de la ONG. Asimismo, la Reserva cuenta con una fuente constante de ingresos y maneja adecuadamente el riesgo por medio de planes de contingencia y el establecimiento de un fideicomiso que protege la operación por 10 años en el caso que su principal fuente de ingresos se contraiga.

En ese sentido, la afluencia de visitantes al área protegida es la principal fuente de ingresos de la reserva, donde la misma ha mostrado un comportamiento creciente en los últimos 15 años (Figura 14), lo cual le ha permitido generar los recursos suficientes para sostener la operación. Sin embargo, es importante recalcar que al ser ésta la única fuente primaria de ingresos de la operación y al ser el turismo una actividad de alto riesgo por su sensibilidad a factores externos como lo son las crisis económicas, lo cual se evidencia en el periodo 2008-2012, la administración entonces debería desarrollar esfuerzos, por un lado, para diversificar sus fuentes de ingresos, y por otro, para diseñar planes de contingencia bajo diferentes escenarios de crisis económicas; así como, ampliar los aportes al

\section{Visitantes}

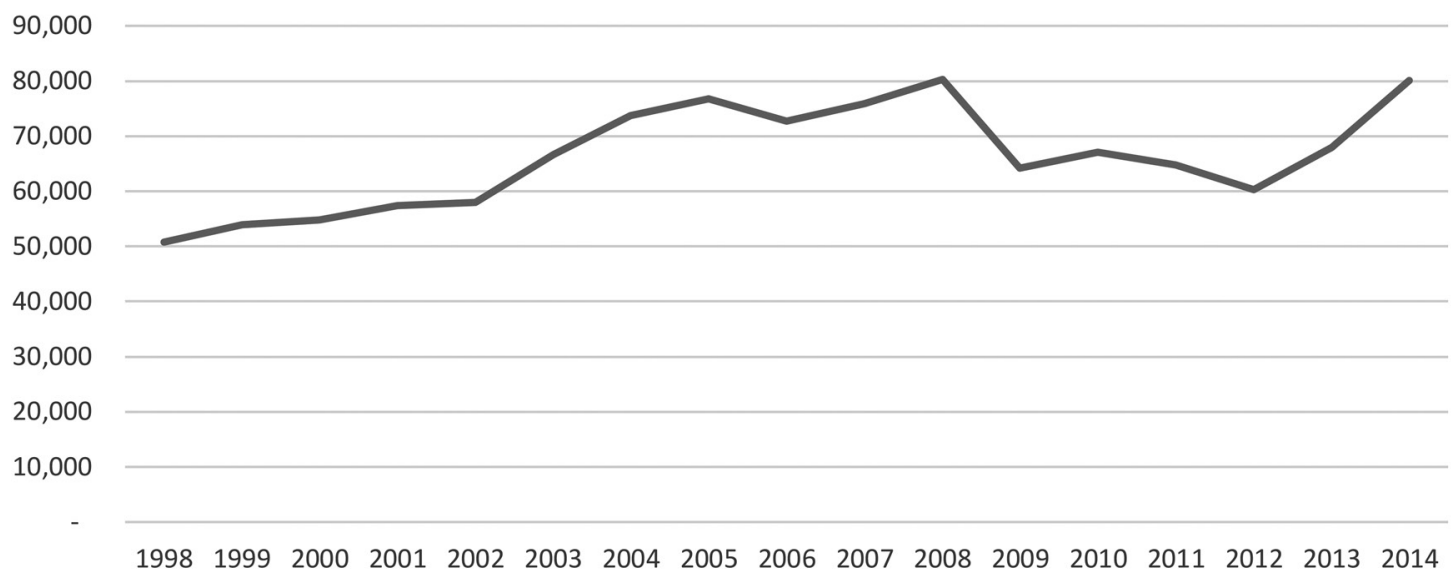

Figura 14. Cantidad de visitantes por año a la Reserva Monteverde, para el periodo 1998-2014. Fuente. Elaboración del grupo de trabajo con información suministrada por la Reserva. 
fideicomiso existente, el cual es una excelente iniciativa para el manejo del riesgo, pero que no asegura la solvencia financiera de la reserva a largo plazo, ya que el plan está dado para que el fideicomiso supla de los recursos suficientes para la protección de la reserva por 10 años.

Los evaluadores consideran que la administración debe ir diversificando sus fuentes de generación de recursos sin perder de vista los objetivos estratégicos, de tal forma que los recursos adicionales que estas fuentes adicionales generen, sean invertidos en fondos de producción de capital, a nivel nacional o internacional, que aseguren la sostenibilidad financiera de la reserva a largo plazo en caso de que se enfrenten a periodos de crisis económicas. De esta forma, como se mencionó en el apartado sobre el medio ambiente, la Reserva podría aprovechar la coyuntura actual sobre el interés de la sociedad en mitigar su huella ambiental, y así, desarrollar mecanismos para ser proveedor de servicios ecosistémicos a cambio de recursos económicos como una medida de diversificación financiera.

\section{Integración de los indicadores}

Al evaluar la reserva agregando los resultados de los indicadores utilizados en cada uno de los ámbitos, se puede apreciar el buen rendimiento que presenta el proyecto en términos de la sostenibilidad global (Tabla 7, Figura 15).

\section{TABLA 7}

\section{Resultados integrados de la sostenibilidad. Reserva Biológica Bosque Nuboso Monteverde. Abril 2015.}

\begin{tabular}{lcc}
\multicolumn{1}{c}{ Ámbito } & Puntaje máximo & Puntaje Obtenido \\
Ambiente & 100 & 94.44 \\
Social & 100 & 98.57 \\
Económico & 100 & 92.50 \\
\hline
\end{tabular}

Fuente. Elaboración del grupo de trabajo.

Los resultados de esta evaluación integrada son un reflejo del esfuerzo auténtico que realiza la administración de la reserva para manejar el área protegida desde una perspectiva técnica, con objetivos claros y medibles en función de la

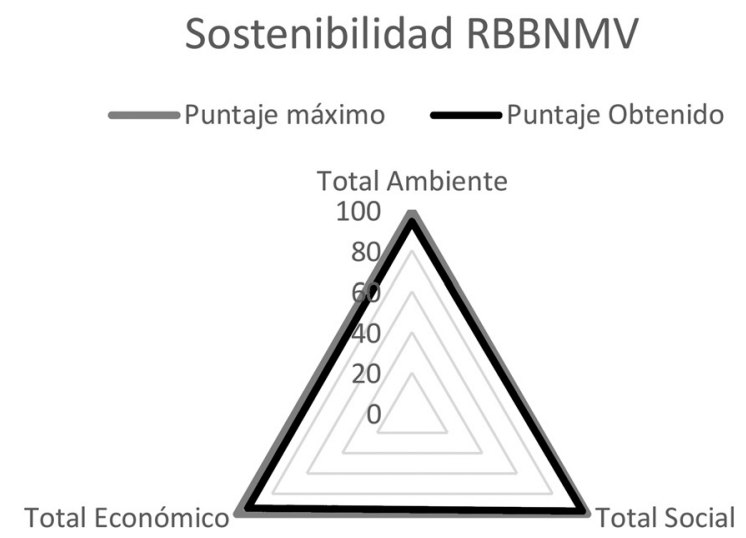

Figura 15. Resultados integrados de la sostenibilidad. Reserva Biológica Bosque Nuboso Monteverde. Abril 2015. Fuente. Elaboración del grupo de trabajo.

sostenibilidad. A partir de las valoraciones realizadas tanto en el campo, como a través de la revisión de la literatura, el equipo de trabajo logró ser testigo que la Reserva Monteverde es un ejemplo auténtico de sostenibilidad. Lo anterior es importante recalcar a pesar que se encontraron áreas en la cuales el proyecto puede mejorar, no se lograron identificar fallas en el sistema de gestión que provocaran dudas sobre la veracidad o validez de la información, ya que a lo largo del proceso evaluativo, la información siempre fue provista en forma fluida y transparente. De esta manera, no queda la menor duda que el concepto de sostenibilidad en la Reserva Monteverde no solo es una moda para mejorar la imagen, y así lograr vender más entradas a los visitantes, por el contrario, es un concepto que está profundamente internalizado en los objetivos y metodologías de operación del área que regula, fiscaliza y potencia su gestión y que ha sido una clave para el éxito del proyecto.

En ese sentido, se considera que han existido una serie de circunstancias y factores críticos que han favorecido el buen desempeño del área protegida en varios términos. De esta forma, tales factores han sido los siguientes:

La Reserva Monteverde como iniciativa de la comunidad: El sentido de pertenencia de la comunidad hacia el bosque protegido ha sido un elemento fundamental para su desarrollo. Este sentido se ha desarrollado debido 
a que el proyecto no fue impuesto por el gobierno, sino que, por una iniciativa de la comunidad local, principalmente cuáquera.

El enfoque que se le otorgó al proyecto como un área protegida en función de la conservación de los Recursos Naturales: La visión de utilizar la reserva como un instrumento para la educación ambiental y la investigación en el manejo de recursos naturales ha sido un elemento clave para el éxito del proyecto. La incursión de la Reserva Monteverde en el ámbito de investigación le ha permitido generar y documentar información científica de gran relevancia como lo es el descubrimiento de nuevas especies, la extinción de especies y los efectos del cambio climático en ecosistemas boscosos.

La planificación como herramienta de gestión: Este ha sido el pilar fundamental de éxito de la Reserva Monteverde. La reserva se maneja bajo un régimen moderno de administración de áreas protegidas que promueve no solo la planificación, sino que el monitoreo y evaluación adaptativa de sus objetivos.

El turismo como fuente de generación de ingresos: El turismo es el motor generador de ingresos que permite la administración efectiva de la Reserva Monteverde. Pero no es un turismo descontrolado, por el contrario, se maneja el concepto de capacidad de carga para lo cual hay un estudio técnico que lo fundamenta (Plan de manejo de visitantes 2009).

Manejo eficiente de recursos: La eficiente administración de recursos les ha permitido, no solo lograr cubrir los costos operativos, sino que también les ha facilitado la consolidación de un fideicomiso de operatividad, el cual se maneja desde 1995. Este fideicomiso asegura la sostenibilidad económica para invertir en recursos humanos que se contrataría para proteger la Reserva por 10 años en caso de que no hubiera afluencia de turismo.

El hecho de ser administrada por una ONG sin fines comerciales y con principios conservacionistas e investigativos (Centro Científico Tropical): Aunque bien es cierto que el CCT se beneficia de los recursos que genera la Reserva Monteverde para su operación a nivel de país, muchos de esos recursos son utilizados para fomentar más conservación e investigación en el resto del territorio nacional.

Autonomía en la generación y manejo de recursos: La autonomía que tiene el proyecto al ser de carácter privado y no depender del gobierno, permite que los fondos generados sean reinvertidos en su propia operación y en la comunidad.

Aceptación que ha recibido a nivel local y nacional: Dado a su estilo de operar y a la labor perenne de conservación, investigación y educación, la población local, nacional y global han siempre visto a la Reserva Monteverde como un aliado fuerte en el tema de conservación y preocupado por los problemas ambientales y socioeconómicos de la región.

Personal capacitado y motivado con la misión y los objetivos de la reserva: El personal de la reserva se ha identificado con los objetivos de la misma lo cual es fundamental para el éxito de toda empresa.

La apertura y disponibilidad de ser un gestor en procesos de desarrollo y conservación hacia lo externo de la Reserva. La reserva no se maneja como una unidad aislada, sino que colabora en proyectos e iniciativas que benefician directa e indirectamente los objetivos de la misma, como por ejemplo ser líder en la conformación del Corredor Biológico Pájaro Campana (www.cbpc.org), aliarse al Sistema Nacional de Áreas de Conservación, ser miembro de la Red de Reservas Privada de Costa Rica. Asimismo, participar en Foros Mundiales sobre el Manejo de Áreas Protegidas, ser parte del Sistema de Certificación para Sostenibilidad Turística, así como del Programa Bandera Azul Ecológica para Áreas Protegidas. Aunque la Reserva Monteverde opera localmente tiene una influencia a nivel regional, nacional y mundial.

Normatividad Costarricense que brinda el marco legal para la conservación: Costa Rica cuenta con marco jurídico e institucional que fomenta la conservación de los recursos naturales permitiendo la operatividad funcional de reservas y áreas protegidas tanto de carácter público como privado.

La administración de la reserva debe ser consciente que existen factores ambientales y socioeconómicos que pueden afectar la sostenibilidad 
futura del proyecto y debe llevar a cabo un proceso de planificación para mitigar los impactos que esos factores puedan tener sobre el área protegida. Así, para los factores ambientales es importante que se contemple:

Fragmentación del hábitat hacia la vertiente Pacífica: El nivel de conectividad boscosa estructural y la calidad del bosque en la Vertiente Pacífica son factores que amenazan la integridad ecológica de la reserva. Esto por cuanto muchas de las especies que habitan el bosque nuboso realizan migraciones altitudinales hacia ambas vertientes para cumplir con ciclos reproductivos o alimenticios, y al encontrarse con un paisaje altamente fragmentado en el lado Pacífico, los ciclos naturales se pueden ver interrumpidos, poniendo en peligro de extinción y erosión genética a muchas especies. En ese sentido la RBBMV se ha unido con un grupo de organizaciones gubernamentales y no gubernamentales de la zona para la conformación del Corredor Biológico Pájaro Campana (www.cbpc.org), con el fin de restablecer la conectividad boscosa promoviendo un desarrollo acorde a esos objetivos de conservación.

Variabilidad climática: El bosque nuboso de Monteverde es uno de los ecosistemas terrestres más amenazados a nivel mundial por la variabilidad climática, ya que es una isla ubicada sobre la cordillera. $\mathrm{Al}$ aumentar la temperatura en esta isla, las especies se ven expuestas a nuevas condiciones ambientales, así como a nuevas enfermedades y competidores, para lo cual muchas de ellas no han desarrollado todavía las adaptaciones que les permitiría mitigar los efectos del cambio. Estas especies tienen dos opciones, o se adaptan a las nuevas condiciones o se extinguen, ya que, al estar en la cima de la montaña, muchas de ellas no pueden migrar. Esto precisamente, según Pounds et al (2006), fue lo que le ocurrió al Sapo Dorado (Incilius periglenes) y a la Rana Arlequín (Atelopus sp.). El aumento de la temperatura favoreció la penetración de un hongo (Batrachochytrium dendrobatidis) que afecta el metabolismo de los anfibios, provocándoles la muerte y consecuentemente la extinción o declinación de ambas especies.
Entre los factores socioeconómicos que se debe prestar atención se encuentran:

El turismo como única fuente de sostenibilidad financiera: Esta es una de las principales fortalezas, pero a la vez una gran debilidad de la Reserva Monteverde, ya que el turismo es una actividad económica de alto impacto ambiental y social si no se maneja adecuadamente y además presenta un alto nivel de riesgo al ser una actividad altamente sensible a las crisis económicas o conflictos globales.

Desarrollo demográfico e inmobiliario a sus alrededores no planificado: Este desarrollo es principalmente de infraestructura para atender el turismo, donde cerca de 70,000 personas visitan la RBBNMV, pero casi otros 130,000 visitan la región como tal anualmente (la población local residente es de aproximadamente 4,500 habitantes). En la zona se cuentan con todos los servicios básicos incluyendo electrificación, agua potable, recolección de basura, seguridad. Sin embargo, no se ha realizado una adecuada planificación urbana, ni tampoco existen servicios de alcantarillado ni tratamiento de aguas residuales post uso. Existe un pequeño Gobierno Local que no tiene la capacidad de gestión para atender las necesidades del distrito. Los impactos ambientales y sociales que se generan en el área de amortiguamiento de la Reserva pueden llegar a desbordarse e incidir en la integridad del área protegida.

El turismo masivo: Si no se planifica y controla el desarrollo de infraestructura y se regula la afluencia de un turismo masivo a la región, el destino puede deteriorarse irreversiblemente como ha ocurrido en Jacó y Tamarindo, ambos destinos en Costa Rica, ya que se puede sobrepasar la capacidad de carga del sistema de conservación. Mientras la afluencia de turismo dentro de los límites de la reserva es controlada, fuera de ella no se controla, más bien cada día se promueve aún más, lo cual es beneficioso desde un punto de vista de crecimiento económico, pero no necesariamente desde el punto de vista de conservación. La Reserva puede tratar de influenciar políticamente este desarrollo, pero no tiene la potestad de frenarlo. Además, este tipo de turismo masivo no atiende a las características 
sociales de la región, favoreciendo la transculturación gracias a la inmigración de personas provenientes de otras regiones que no cuentan necesariamente con los valores ni son parte de la idiosincrasia local. Asimismo, este tipo de turismo favorece la competencia desleal creando sistemas de corrupción turística donde los recepcionistas de los hoteles y operadores de turismo reciben sobornos masivos por parte de los empresarios para dirigir a los turistas hacia sus negocios, los cuales no respetan necesariamente los parámetros de calidad del sector causando deterioro en la calidad de los servicios y de la imagen del lugar, volviéndolo más caro y menos atractivo para los visitantes.

La poca capacidad de gestión del Gobierno Local y otras autoridades gubernamentales del sector: Así como la Reserva Monteverde tiene un sistema de manejo de su área protegida, el distrito debería tener un plan de desarrollo local fundamentado en la conservación y la adecuada explotación de los recursos a través del turismo, la agricultura y el comercio. Sin embargo, esta planificación no existe. Peor aún, la capacidad de gestión del Gobierno Local es sumamente limitada y no tienen la fuerza suficiente para adelantarse al desarrollo explosivo que está experimentando el distrito.

\section{Conclusiones}

La principal fortaleza administrativa de la Reserva Monteverde ha sido su capacidad de planificación basada en información técnicocientífica que es generada a lo interno y a lo externo del área protegida; mientras que su principal rasgo social ha sido la proyección hacia la comunidad a través del programa de educación ambiental, en tanto su principal fortaleza económica ha sido la adecuada administración de los recursos generados a través de la afluencia de visitantes al área protegida.

La integración de sus principales fortalezas, le ha permitido a la Reserva Monteverde cumplir con los objetivos de conservación en forma eficaz logrando la protección de uno de los ecosistemas más particulares y frágiles del planeta. Esto ha provocado que, por un lado, el área natural se haya convertido en un ejemplo exitoso de conservación de clase mundial, y por otro, que se haya generado un interés por parte del público en visitar la reserva, el cual lo hace con los deseos de descubrir los misterios que guarda el bosque nuboso, factor que ha sido clave para producir los recursos suficientes para operar y mantener en funcionamiento el área protegida y así lograr sus objetivos.

Independientemente de los factores que hayan influenciado el éxito de la Reserva Monteverde, así como de los elementos o circunstancias que puedan afectar el rendimiento futuro del proyecto, ha quedado evidenciado, en este estudio de caso, que la sostenibilidad, como elemento transformador, está profundamente arraigada en el sistema de gestión de esta área protegida. Este elemento ha sido el motor de la innovación, y deberá seguir siendo uno de los principales mecanismos para mantener y proyectar el éxito del proyecto hacia el futuro.

\section{Recomendaciones}

La principal recomendación que el equipo evaluador puede brindar al equipo administrativo de la Reserva Monteverde, es la de continuar implementando el modelo actual de gestión basado en la planificación técnica para el alcance de los objetivos del proyecto y tomando en cuenta los siguientes aspectos:

En términos operativos, la administración de la reserva debe ser consciente que es necesario desarrollar mecanismos para cimentar su sostenibilidad financiera a través de la diversificación de sus fuentes de generación de recursos; esto sin perder de vista los objetivos de conservación, de tal forma que el crecimiento económico sea un medio para alcanzar las metas y no un fin.

Desde la perspectiva de protección del ecosistema, es recomendable que la reserva continúe integrada como uno de los principales actores del Corredor Biológico Pájaro Campana, esto con el fin de mejorar la conectividad boscosa estructural en la vertiente Pacífica del área de amortiguamiento de la reserva y asegurar, hasta donde las condiciones lo permitan, la integridad del ecosistema protegido. 
Desde el punto de vista de adaptación a la variabilidad climática, se recomienda elaborar un plan de adaptación a dicho fenómeno para efectos del manejo de la operación, pero también se recomienda desarrollar estudios a nivel ecológico que permitan conocer los cambios potenciales que puede sufrir el ecosistema y desarrollar las medidas para tratar de proteger el mayor número de especies de la extinción.

En función de los aspectos sociales, la administración de la reserva debe procurar tener una mayor incidencia a nivel local y hacer uso de su autoridad moral para exigir, por parte del gobierno local, las autoridades locales, el sector empresarial y la ciudadanía que se beneficia directamente o indirectamente del área protegida, que haya una planificación efectiva del desarrollo turístico a corto, mediano y largo plazo, y de esta forma salvaguardar la integridad ecológica, económica y social del Bosque Nuboso de Monteverde, de los efectos nocivos de la mala o ausente planificación y del turismo masivo.

Para efectos de futuras investigaciones se recomienda la exploración del impacto que tiene la Reserva Biológica Bosque Nuboso Monteverde las comunidad circunvecinas.

\section{Bibliografía consultada}

Acuña, M. A., Villalobos, D., y Ruiz, K. (2006). Ecoturismo, ambiente y desarrollo local en Monteverde. Ciencias Ambientales UNA, (31), 5-20.

Armenteras, D., Cadena, V.C. y Moreno, R.P. 2007. Evaluación del estado de los bosques de niebla y de la meta 2010 en Colombia. Bogotá, Colombia: Instituto de Investigación de Recursos Biológicos Alexander von Humboldt. 72p.

Astier, M., Masera, O., Galván, Y. 2008. Evaluación de Sustentabilidad. Un enfoque dinámico y multidimensional. Valencia, España: IMAG Impressions.

Bermúdez, E. y Hernández, C. 2005. Plan de Manejo de la Reserva Biológica Bosque Nuboso Monteverde. San José, Costa Rica: Centro Científico Tropical.

Bermúdez, E. y Hernández, C. 2007. Plan de Ordenamiento del Uso Turístico de la Reserva Biológica Bosque
Nuboso Monteverde. Plan de Atención de Visitantes. San José, Costa Rica: Centro Científico Tropical.

Chacón, O. 2010. Mapa de Áreas Silvestres Protegidas de Costa Rica. Heredia, Costa Rica: USIG-INBio.

Corredor Biológico Pájaro Campana (CBPC). 2011. Plan estratégico 2011-2016. Monteverde, Puntarenas, Costa Rica: Concejo Local del CBPC.

Corredor Biológico Pájaro Campana (CBPC). 2013. Mapa de uso actual del suelo en el Corredor Biológico Pájaro Campana. Monteverde, Puntarenas, Costa Rica: Concejo Local del CBPC.

Ocampo-Peñuela, N. (Editora). 2010. Mecanismos de Conservación Privada: una opción viable en Colombia. Bogotá, Colombia: Grupo Colombiano Interinstitucional de Herramientas de Conservación Privada.

Pounds, J. A, Bustamante, M, R., Coloma, L.A., Consuegra, J. A., Fogden, MP. L., Foster, P.N., La Marca, E., Masters, K. L., Merino-Viteri, A., Puschendorf, R., Ron, S.R., Sánchez-Azofeifa, G.A., Still, C.J., Young, B. 2006. Widespread amphibian extinctions from epidemic disease driven by global Warming. Nature 439, 161-167. doi:10.1038/nature04246

Roldan, M.; Carminati, A.; Biganzoli, F. y Paruelo, J. M. 2010. Las reservas privadas ¿son efectivas para conservar las propiedades de los ecosistemas?. Ecología Austral 20 (2).

Sistema Nacional de Áreas de Conservación (SINAC). 2011. Políticas para las Áreas Silvestres Protegidas (ASP) del Sistema Nacional de Áreas de Conservación de Costa Rica. San José, Costa Rica: SINAC

Sistema Nacional de Áreas de Conservación (SINAC). (2012). Plan de Acción para la Implementación del Programa de Trabajo sobre Áreas Protegidas de la Convención sobre la Diversidad Biológica. San José, Costa Rica: SINAC.

Toledo, T. 2009. El bosque de niebla. Biodiversitas 83:1-6

Wheelwright, N. T. y Nadkarni, N. M. (editores). 2014. Monteverde: ecología y conservación de un bosque nuboso tropical. Recuperado de http://digitalcommons.bowdoin.edu/scholars-bookshelf/3/ 